\title{
A Review on the Efficiency of Graphene-Based BHJ Organic Solar Cells
}

\author{
Alejandro Manzano-Ramírez, ${ }^{1}$ Edgar J. López-Naranjo, ${ }^{2}$ \\ Wole Soboyejo, ${ }^{3}$ Yunny Meas-Vong, ${ }^{4}$ and Bertrand Vilquin ${ }^{5}$ \\ ${ }^{1}$ CINVESTAV-IPN Unidad Querétaro, 76230 Santiago de Querétaro, QRO, Mexico \\ ${ }^{2}$ Universidad Autónoma de Nayarit, Ciudad de la Cultura Amado Nervo s/n, 63190 Tepic, NAY, Mexico \\ ${ }^{3}$ Princeton Institute of Science and Technology of Materials (PRISM), Bowen Hall, 70 Prospect Street, Princeton, NJ 08544, USA \\ ${ }^{4}$ CIDETEQ, Parque Tecnológico Querétaro Sanfandila, 76703 Pedro Escobedo, QRO, Mexico \\ ${ }^{5}$ Univertisté de Lyon, École Centrale de Lyon, Institut des Nanotechnologies de Lyon, 36 Avenue Guy de Collongue, \\ 69134 Ecully Cedex, France
}

Correspondence should be addressed to Alejandro Manzano-Ramírez; amanzano@cinvestav.mx

Received 19 May 2015; Revised 30 August 2015; Accepted 31 August 2015

Academic Editor: Michal Otyepka

Copyright (C) 2015 Alejandro Manzano-Ramírez et al. This is an open access article distributed under the Creative Commons Attribution License, which permits unrestricted use, distribution, and reproduction in any medium, provided the original work is properly cited.

\begin{abstract}
Graphene, a material composed of one-atom-thick planar sheets of $\mathrm{sp}^{2}$-bonded carbon atoms with a two-dimensional honeycomb structure, has been proposed for many applications due to its remarkable electronic, optical, thermal, and mechanical properties. Its high transparency, conductivity, flexibility, and abundance make it an excellent material to be applied in the field of organic photovoltaic cells, especially as a replacement for transparent conducting oxide electrodes. However, graphene has been demonstrated to be useful not only as substitute for indium tin oxide electrodes, but also as cathode, electron acceptor, hole transport, and electron extraction material. Thus, in this work, we summarize and discuss the efficiency of bulk heterojunction devices using graphene as a main constituent.
\end{abstract}

\section{Introduction}

Organic solar cells (OSCs) belong to the class of photovoltaic devices known as excitonic solar cells, which are characterized by strongly bound electron-hole pairs (excitons) that are formed after excitation with light. Strongly bound excitons exist in these materials as a consequence of the low dielectric constants in the organic components, which are insufficient to affect direct electron-hole dissociation, as it is found in their high dielectric inorganic counterparts. In excitonic solar cells, exciton dissociation occurs almost exclusively at the interface between two materials of different electron affinities (and/or ionization potentials): the electron donor and the electron acceptor. To generate an effective photocurrent in these organic solar cells, an appropriate donor-acceptor pair and device architecture must be selected. Two main approaches have been explored in the effort to develop viable devices: the donor-acceptor bilayer and the socalled bulk heterojunction (BHJ), which is represented in the ideal case as a bicontinuous composite of donor and acceptor phases, thereby not only maximizing the donor/acceptor interface for efficient exciton dissociation, but also forming a nanoscale interpenetrating network for charge transport to the electrodes [1,2] (Figure 1). Organic solar cell research and device development still have a long way to go to compete with inorganic solar cells. The efficiency of inorganic devices can top 20\% and the development of inorganic thin-layer and multijunction instruments will likely lead to even better performance. In contrast, the best OSCs, based on the BHJ concept, operate at a maximum of $\sim 8.0 \%$ efficiency. However, due to its low cost, lightweight, high availability of materials, and easy manufacturing, the OSCs technology turns very appealing as it could theoretically produce highly efficient devices [3-5]. 


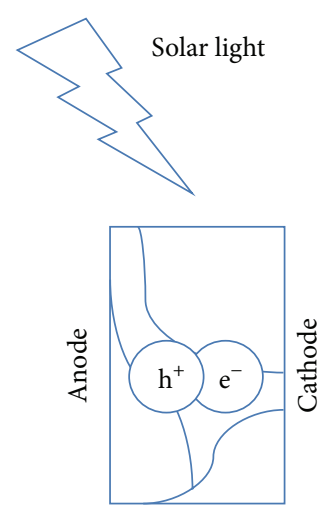

(a)

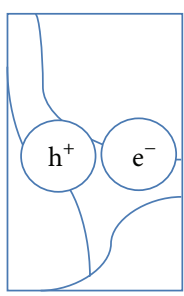

(b)

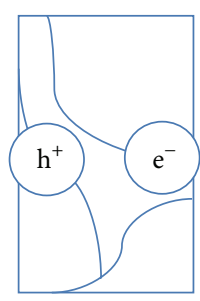

(c)

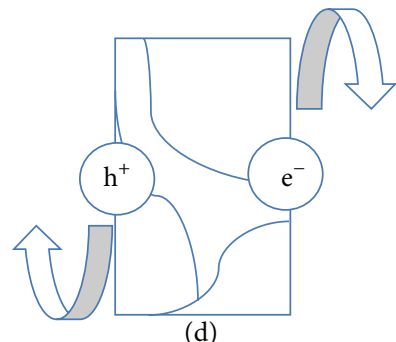

(d)

FIGURE 1: BHJ cell operation mechanism. (a) Exciton generation, (b) exciton dissociation, (c) charge formation, and (d) charge transport and collection.

Based on the simple consideration that low band gap materials have the possibility to improve the efficiency of photovoltaic devices due to a better overlap with the solar spectrum, it is expected that, for a maximum photon harvesting in the OSCs, low band gap materials will be employed. The use of this type of materials results in higher currents that can lead to higher power conversion efficiency (PCE). Poly3-hexylthiophene ( $\mathrm{P} 3 \mathrm{HT})$, one of the most used materials as donor in a BHJ device, exhibits a band gap of $650 \mathrm{~nm}(1.9 \mathrm{eV})$ and thus only has the possibility to harvest up to $22.4 \%$ of the available photons giving a maximum theoretical current density of $14.3 \mathrm{mAcm}^{-2}$. If P3HT is applied in a BHJ device, coupled with the most commonly used acceptor (i.e., phenyl$\mathrm{C}_{61}$-butyric acid methyl ester, PCBM), the band gap extends to $1000 \mathrm{~nm}$ allowing for absorption of $53 \%$ of the available photons giving a maximum current density of $33.9 \mathrm{mAcm}^{-2}$. However, in practical terms these values cannot be achieved and the real performance of a $\mathrm{P} 3 \mathrm{HT}$ : $\mathrm{PCBM}$ system is around its optimal of about $5 \%$ which is lower than a quarter of a silicon solar cell's optimal $[6,7]$.

Graphene, a zero-band-gap semiconductor is a rising star in materials science (Figure 2). It shows a two-dimensional (2D) structure consisting of $\mathrm{sp}^{2}$-hybridized carbon and it is also the thinnest known material in the universe and the strongest ever measured [8-11]. It exhibits remarkable electronic and mechanical properties and a considerable number of new optical effects that have not been observed in other materials [12, 13]. Its remarkably high carrier mobility, wide absorption spectral range, and high optical transparency indicate graphene as a cost-effective and abundant material that qualifies for application in optoelectronic devices such as displays, light-emitting diodes, and solar cells [14-17].

Different routes are available for the preparation of graphene $[12,18,19]$. The first involves chemical vapor deposition (CVD) of monolayer of graphite on transition metal surfaces $[20,21]$. The second route is the micromechanical exfoliation of graphite and involves peeling of the graphene from graphite using "Scotch" tape [22]. The "Scotch" tape is then dipped in acetone to release the graphene, which is subsequently captured on a silicon wafer with a $\mathrm{SiO}_{2}$

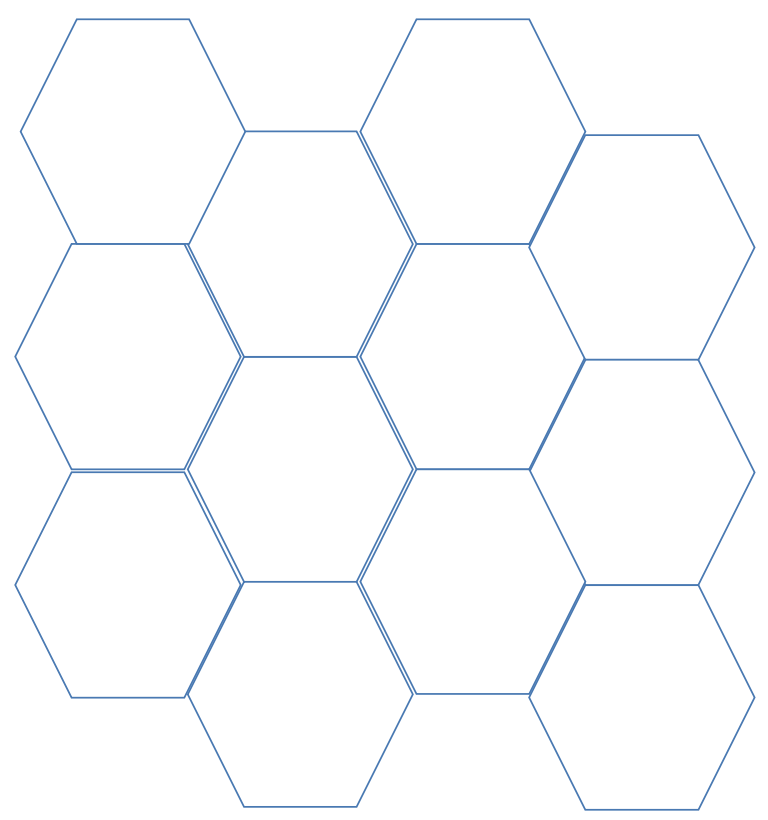

FIGURE 2: Representation of graphene structure.

(silicon dioxide) layer on top. The third route involves the epitaxial growth of graphene on electrically insulating substrates like silicon carbide [23]. However, the second and third methods are unsuitable for large-scale preparation of graphene for the fabrication of polymer nanocomposites [19]. Thus, it appears that the only routes to prepare bulk quantities of graphene and chemically modified graphene $(\mathrm{CMG})$ are from graphene oxide (GO) and graphite intercalation compounds (GICs). The presence of hydroxyl and epoxide groups on the graphitic basal planes and carboxyl and carbonyl groups on the edges of layers makes GO water dispersible [24]. Thus, on sonication in aqueous media, GO exfoliates readily into colloidal suspensions of single graphene oxide layers. Chemical reduction of GO present in the colloidal suspension with reducing agents is necessary to convert the electrically insulating GO layers back to conducting graphene 
suitable for composite applications. The final route by which bulk quantities of graphene can be prepared is by thermally reducing GO. This technique involves rapidly heating GO in inert (argon or nitrogen) environment to produce thermally reduced expanded graphene oxide (TRGO) $[25,26]$. Due to its wrinkled nature, TRGO do not collapse back to GO but remain highly agglomerated. However, McAllister et al. [27] observed that, after TRGO was dispersed by ultrasonication in appropriate solvents, $80 \%$ of the flakes were single graphene sheets.

Derivatives of graphene, such as GO and reduced graphene oxide (rGO), are also being widely investigated from the point of view of primary and practical applications [16]. rGO can be easily prepared by wet processes such as spin-, dip-, and spray-coating to give large-area GO films and by hydrazine vapor treatment to reduce the GO films. Secondary treatments, such as thermal annealing, have been indicated to increase the photocurrent and device efficiency by removing defects and optimizing the morphology of graphene-based cell constituents $[2,16]$.

Regarding the PCE in $\mathrm{BHJ}$ devices, the highest value was observed to be $\sim 7.4 \%$ for the device with ITO/PEDOT: PSS/ PBTTT-3: $\mathrm{PC}_{70} \mathrm{BM} / \mathrm{Ca} / \mathrm{Al}$ (indium tin oxide/poly(3,4-ethylenedioxythiophene) : poly(styrenesulfonate)/poly(2,5-bis(3: tetradecylthiophen-2-yl)thieno(3,2-b)thiophene)/3: phenyl$\mathrm{C}_{70}$-butyric acid methyl ester/calcium/aluminum) structure [16]. Photovoltaic devices based on graphene are still not as efficient as, for example, devices with ITO electrodes or organic acceptors mainly because the conductivities of graphene are relatively low $[9,28]$. Theoretical PCEs as high as $12 \%$ have been calculated for graphene-based organic devices [29], and it has also been proposed that graphene may favor charge carrier multiplication [30]. Graphene has proved to be useful not only as substitute for ITO electrodes, but also as cathode, electron acceptor, hole transport, and electroextraction material (Figure 3) [15, 31, 32]. Therefore, this review is intended to examine the efficiency of different graphene-based devices and the newest trends in order to maximize their efficiencies.

\section{Electrode Material}

In $\mathrm{BHJ}$ devices, the conventional transparent conductive electrode used to couple photons into the active layer is extensively the ITO-based electrode that shows a sheet resistance of less than $100 \Omega /$ sq and an optical transparency of $\sim 90 \%$ $[2,33]$. ITO electrodes consume as much as $30 \%$ of the fabrication cost in solar cells and their use seems to be increasingly problematic due to the limited indium source, susceptibility to ion diffusion into polymer layers, instability in acid or base, and the brittle nature of metal oxide [34-36]. Additionally, Krebs et al. reported that the energy involved in processing the ITO electrode accounts for $87 \%$ in roll-to-roll based OSCs fabrication [37]. Thus, a substitute for ITO with similar performance but lower cost is clearly needed. In this regard, graphene has risen as a promising electrode material due to its high theoretical surface area of $2630 \mathrm{~m}^{2} / \mathrm{g}$ and ability to facilitate electron or hole transfer along its two-dimensional

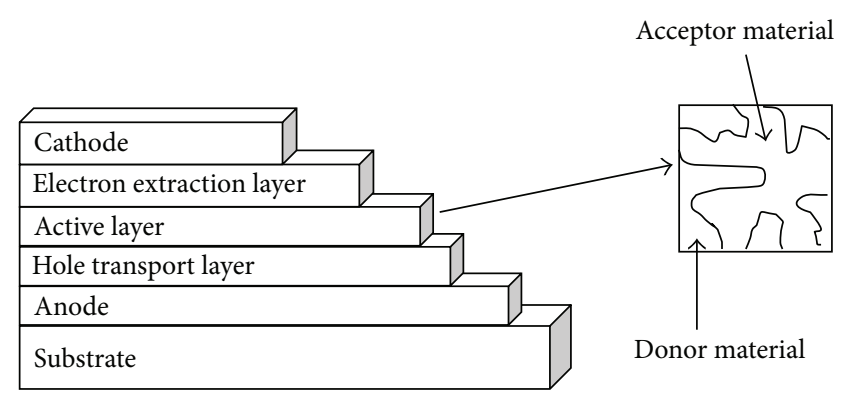

FIGURE 3: Configuration of a typical BHJ solar cell.

surface $[13,22,35]$. The high transparency, conductivity, flexibility, and elemental abundance of graphene indicate that it is an excellent replacement for transparent conducting oxide electrodes [38-40]. Graphene transparent electrodes can be expected to be applied not only for the substitution of ITO that is usually used as anode but also for cathode for which low work function metals are used [41, 42].

However, for chemically processed graphene, mainly the contact resistance of the small graphene flakes and the insulating property of the graphene chemically reduced from graphene oxide limit the device performance. The structural defects and lateral disorder of such chemically exfoliated graphite affect the carrier mobility of the film negatively [43]. Therefore, although graphene could provide a lowcost alternative for ITO, there is still tremendous room for improvement in terms of enlarging the lateral scale of graphene in these devices [44].

2.1. Anode. Xu et al. [45] reported on polymer organic photovoltaic cells using pure graphene films as the transparent anode directly fabricated from graphene solutions by spincoating, with P3HT as the electron donor and PCBM as the acceptor. The graphene films reduced with hydrazine and annealed at temperatures of 300,500 , and $700^{\circ} \mathrm{C}$ had transmittance of $75 \%, 73 \%$, and $69 \%$ at a wavelength of $550 \mathrm{~nm}$, respectively. Under these experimental conditions, the reduced graphene films could have a sheet resistance of $17.9 \mathrm{k} \Omega / \mathrm{sq}$ and a conductivity of $22.3 \mathrm{~S} / \mathrm{cm}$ which is comparable with that obtained using more complicated graphene composites. The current density-voltage $(J-V)$ characteristic of the device (hydrazine $+700^{\circ} \mathrm{C}$ ) under illumination of simulated solar light shows a short-circuit photocurrent density $\left(J_{s c}\right)$ of $1.18 \mathrm{~mA} / \mathrm{cm}^{2}$ with an open circuit voltage $\left(V_{o c}\right)$ of $0.46 \mathrm{~V}$, a calculated filling factor (FF) of $24.58 \%$, and an overall PCE of $0.13 \%$. The ITO device used as a reference was fabricated under the same conditions and had a PCE of 3.59\%. The low PCE of the graphenebased device is likely due to the hydrophobic graphene film surface which makes it rather hard to get a uniform poly(3,4-ethylenedioxythiophene) : poly(styrenesulfonate) (PEDOT: PSS) layer. So, it is highly possible that, with optimized graphene-electrode conductivity and graphene film surface wetting property, the performance of these graphene-electrodes cells could be improved significantly [45]. Although this approach provides a cost-effective, simple 
solution-based process, the overall PCE of the graphenebased device is lower than that reported for the best OSCs based on the $\mathrm{BHJ}$ concept ( 8.0\%).

Yin et al. [34] indicated that the performance of the organic devices mainly depends on the charge transport efficiency through rGO electrodes when the optical transmittance of rGO is above $65 \%$. However, if the transmittance of rGO is less than $65 \%$, the performance of the device is dominated by the light transmission efficiency, that is, the transparency of rGO films. In this work, highly conductive rGO film was transferred onto a polyethylene terephthalate (PET) substrate, which was used as the transparent electrode. The authors reported that lowering the rGO sheet resistance via increasing the rGO thickness notably enhanced the current density of devices and thus the overall PCE. In order to study the effect of rGO thickness on the performance of the devices, rGO films with different thickness were prepared $(4 \mathrm{~nm}, 10 \mathrm{~nm}, 16 \mathrm{~nm}$, and $21 \mathrm{~nm})$. The highest optical transmittance, $88 \%$, was obtained in the $4 \mathrm{~nm}$ thick rGO films, but the sheet resistance dramatically increased to $16.0 \mathrm{k} \Omega / \mathrm{sq}$. The highest PCE obtained in the flexible $\mathrm{rGO} / \mathrm{PET}$ devices was $0.78 \%$ and corresponded to the $16 \mathrm{~nm}$ thick rGO cells, which showed the highest $J_{\mathrm{sc}}$ and $V_{\mathrm{oc}}$. These devices showed an excellent stability after applying the bending-induced tension stress, and their performance was well maintained even after bending a thousand times [34].

Wang et al. [46] described the fabrication and characterization of transparent graphene-constructed films (TGFs) to be used as hole collecting electrodes in organic solar cells. The transparency of TGFs on quartz was tuned by controlling the film thickness by varying the solution concentration. Different thicknesses $(30,22,12$, and $4 \mathrm{~nm})$ had transmittance of $55,66,80$, and 90 , respectively, at a wavelength of $500 \mathrm{~nm}$. The electrical characteristics of the as-prepared $30 \mathrm{~nm}$ thick TGFs were evaluated by a four-point probe measurement, which showed resistance of $1.6 \mathrm{k} \Omega / \mathrm{sq}$ and a conductivity of $206 \mathrm{Scm}^{-1}$. To demonstrate how the TGFs performed as anodes, organic solar cells were fabricated using a blend of P3HT and PCBM. The photoactive composite layer was sandwiched between TGFs/quartz and Ag electrode. The TGFs on quartz had a sheet resistance of $18 \mathrm{k} \Omega / \mathrm{sq}$ and a transmittance of $85 \%$ at $500 \mathrm{~nm}$. The devices were illuminated with monochromatic light and the highest external quantum efficiency (EQE) of around 43\% was achieved at a wavelength of $520 \mathrm{~nm}$. This efficiency is comparable to the highest EQE value of $47 \%$ for a reference device fabricated under similar conditions but with ITO/glass as the anode. The current-voltage $(I-V)$ characteristics of the device showed a distinct diode behavior under monochromatic light with a wavelength of $510 \mathrm{~nm}$. In this case, PCE was of $1.53 \%$, and under simulated solar light PCE was $0.29 \%$ [46].

Wang et al. [44] produced large area, continuous, transparent, and highly conducting few-layered graphene films (FLGFs) by chemical vapor deposition method to be used as anode for application in photovoltaic devices. In the solutionprocessed organic solar cells, the anode layer should possess good hydrophilicity to allow the spreading of the hole transport layer. In order to tune the surface wettability without degrading the conductivity, the graphene film was noncovalent modified with pyrene buanoic acid succidymidyl ester (PBASE) as a result; the PCE was of $1.71 \%$. This performance corresponds to $\sim 55.2 \%$ of the PCE of a control device based on an ITO anode. The electronic energy levels of graphene before and after modification with PBASE were investigated; the results indicated that graphene maintained a nearly zerogap condition after the treatment. Thus, since the main drawback of graphene film is its poor hydrophilicity, which led to a negative effect on the construction of solution-processed devices, PBASE treatment resulted to be an effective method to overcome this issue successfully [44].

Gómez De Arco et al. [47] reported on the implementation of continuous, highly flexible, and transparent graphene films obtained by CVD and used as transparent conductive electrodes. The thickness of CVD graphene was on the order of 1-3 nm. According to the authors, the use of CVD graphene is more attractive than the other graphene films, for example, those that are formed by stacked micrometer sized flakes that suffer from flake to flake contact resistance and high roughness. In the case of CVD graphene, the grain boundaries have the advantage of being formed in situ during synthesis; such process is expected to minimize contact resistance between neighboring graphene domains and may result in smoother films with better conducting properties. Solar cells made with CVD graphene exhibited performance that compares to ITO device and surpasses that of ITO devices under bending conditions, exhibiting PCE of $1.18 \%$, which is nearly $93 \%$ of that shown by the ITO device. Contrary to the conventional materials used in BHJ OSCs, in this case, the multilayered configuration employed a copper phthalocyanine $(\mathrm{CuPc})$, fullerene $\left(\mathrm{C}_{60}\right)$, and bathocuproine (BCP) mixture as active layer [47].

Jung et al. [48] reported the characteristics of two different types of OSCs fabricated on $\mathrm{HNO}_{3}$ - (nitric acid-) treated and untreated multilayer graphene (MLG) transparent electrodes prepared using chemical vapor deposition and a multitransfer process. MLG films were formed by stacking graphene films three times on the same substrate and were used as the device anodes. OSCs fabricated on untreated transparent electrodes had a $V_{\text {oc }}$ of $0.575 \mathrm{~V}$, a $J_{\text {sc }}$ of $8.08 \mathrm{~mA} / \mathrm{CM}^{2}$, FF of $43.5 \%$, and a PCE of $2.02 \%$. In contrast, application of $\mathrm{HNO}_{3}$-treated films as transparent electrodes led to an improved performance with a $V_{\text {oc }}$ of $0.602 \mathrm{~V}$, a $J_{\text {sc }}$ of $8.26 \mathrm{~mA} / \mathrm{cm}^{2}, \mathrm{FF}$ of $5.75 \%$, and a PCE of $2.68 \%$. The results suggested that $\mathrm{HNO}_{3}$ treatment is a promising method improving the performance of large-area OSCs [48].

Choe et al. [49] presented the results of applying multilayer graphene (MLG) films as transparent conductive electrodes. The MLG films were synthesized into a CVD chamber under a flow of $\mathrm{H}_{2}$ in Ar gas mixture at different growth temperatures. MLG films prepared at 800,900 , and $1000^{\circ} \mathrm{C}$ showed the sheet resistances of $1730 \pm 600,990 \pm 400$, and $610 \pm 140 \Omega /$ sq and the mobility of $660 \pm 270,1030 \pm 440$, and $1180 \pm 260 \mathrm{~cm}^{2} / \mathrm{V} \mathrm{s}$, respectively. The performance of the devices with $1000^{\circ} \mathrm{C}$ grown MLG films was found to be the best with a PCE of $\sim 1.3 \%$. The PCE was further enhanced when a hole-blocking titanium suboxide $\left(\mathrm{TiO}_{x}\right)$ layer was 
TABLE 1: PCE of BHJ OSCs using graphene as anode.

\begin{tabular}{|c|c|c|c|}
\hline Material & Device conformation & Highest PCE & Reference \\
\hline TGFs & Quartz/TGFs/P3HT : PCBM/Ag & $1.53 \%$ & {$[46]$} \\
\hline FLGFs & FLGFs/PEDOT : PSS/P3HT : PCBM/LiF/Al & $1.71 \%$ & {$[44]$} \\
\hline Graphene & Quartz/graphene/PEDOT : PSS/P3HT : PCBM/LiF/Al & $0.13 \%$ & [45] \\
\hline rGO & PET : rGO : PEDOT : PSS/P3HT : $\mathrm{PCBM} / \mathrm{TiO}_{2} / \mathrm{Al}$ & $0.78 \%$ & {$[34]$} \\
\hline Graphene & PET : CVD graphene/PEDOT : PSS/CuPc/ $\mathrm{C}_{60} / \mathrm{BCP} / \mathrm{Al}$ & $1.18 \%$ & [47] \\
\hline MLG & Glass/MLG/PEDOT : PSS/P3HT : $\mathrm{PCBM} / \mathrm{TiO}_{x} / \mathrm{Al}$ & $2.6 \%$ & [49] \\
\hline CCG & CCG/PEDOT : PSS/P3HT : PCBM/Al & $1.01 \%$ & {$[51]$} \\
\hline MLG & $\mathrm{MLG} / \mathrm{MoO}_{3}+\mathrm{PEDOT}: \mathrm{PSS} / \mathrm{P} 3 \mathrm{HT}: \mathrm{PCBM} / \mathrm{LiF} / \mathrm{Al}$ & $2.5 \%$ & {$[36]$} \\
\hline MLG & MLG/PEDOT $:$ PSS/P3HT : PCBM/Ca/Al & $2.68 \%$ & {$[48]$} \\
\hline MLG & Glass/MLG/PEDOT: PSS/P3HT: PCBM/Ca/Al & $1.17 \%$ & {$[50]$} \\
\hline
\end{tabular}

inserted in the device structure, resulting in a PCE of $\sim 2.6 \%$ which is a significantly higher efficiency compared to the other graphene-based photovoltaic cells [49].

Choi et al. [50] fabricated OSCs based on MLG electrodes, which were prepared using the CVD method and a multitransfer process on a glass substrate. The MLG electrode transferred onto a glass substrate showed a sheet resistance of $374 \pm 3 \Omega /$ sq and an optical transparency of $84.2 \%$. The sheet resistance of the MLG (4 layers) film was higher than those reported elsewhere because in this case no chemical treatment was performed on the film. The transparency of the MLG film was fairly constant regardless of wavelength, unlike the conventional ITO film showing transparency modulation in the blue wavelength region. To prepare the MLG electrode on glass, a thin layer of graphene was grown on $\mathrm{Cu}$ foils using CVD; the transfer process was repeated four times on the transparent glass substrate until the MLG film was obtained. The PCE of the BHJ device was $1.17 \%$, indicating that MLG films are a promising indium-free transparent electrode substitute for the conventional ITO electrode for use in cost-efficient OSCs [50].

Wang et al. [36] developed a direct layer-by-layer (LBL) transfer method of graphene sheets to fabricate MLG films. Stacking multilayers together and doping them rendered higher extrinsic conductivity. $\mathrm{HCl}$ was used to dope the individual layers during the transfer process, followed by $\mathrm{HNO}_{3}$ doping at the surface. Different types of devices were fabricated to evaluate the effect of the various treatments proposed in this work. To improve the hydrophilicity of graphene, a thin layer of $(\sim 20 \AA)$ molybdenum oxide $\left(\mathrm{MoO}_{3}\right)$ was evaporated on the graphene. The as-grown graphenebased devices showed a poor performance, yielding a low PCE of $0.35 \%$. After modifying the graphene with MoO3 + PEDOT:PSS double interfacial layer, the PCE was dramatically increased and $1.23 \%$ was achieved. Finally, the 4-layer acid-doped graphene solar cell exhibited the best performance in this work with PCE of $2.5 \%$, which is about $83.3 \%$ that of the control device fabricated on ITO. The LBL, acid-doped, four-layer graphene film has a sheet resistance of

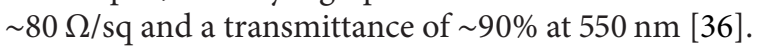

Geng et al. [51] reported a simple method for preparing transparent conductive films using a chemically converted graphene (CCG) suspension via controlled chemical reduction of exfoliated $\mathrm{GO}$ in the absence of dispersant to be used as transparent electrodes in $\mathrm{BHJ}$ devices. After vacuum filtration of the reduction-controlled CCG suspension and subsequent thermal annealing (optimal conditions were $15 \mathrm{~min}$ at $800^{\circ} \mathrm{C}$ ) of the CCG films, high conductive films with a low sheet resistance on the order of $10^{3} \Omega /$ sq and high transparency $(80 \%$ at $550 \mathrm{~nm})$ were obtained. Thermally annealed CCG film showed a sheet resistance that was lower than that of the thermally annealed GO films, apparently due to the greater extent restoration of the $\mathrm{sp}^{2}$ carbon networks during the two-step reduction of the CCG films. Devices prepared with the CCG films as transparent electrodes exhibited PCE of $1.01 \pm 0.05 \%$, which correspond to half the efficiency of solar cell devices in which the electrode was made using ITO [51].

Table 1 summarizes the best PCE achieved by the different research groups presented in the previous section as well as the device conformation that rendered such PCE.

Although the overall PCE obtained by devices using graphene-based materials as anode has not surpassed that of cells using traditional materials, research groups around the world have already identified the main aspects to improve graphene-based materials performance. It has been pointed out that lowering graphene sheet resistance will increase the overall PCE of the BHJ devices. In order to lower the sheet resistance, different strategies can be followed, for example, increasing the thickness of the graphene film. This goal can be achieved following a simple procedure that consists in the modification of the solution concentration from which the film is obtained. This route constitutes a very good option due to its simplicity and to the fact that no additional chemicals are needed, contrary to other techniques that require highly dangerous chemical agents to dope graphene. Thickness control also has an impact on the transparency of the film. A higher transparency will originate a better light transmission and a higher PCE. Thus, a proper balance between transparency and sheet resistance needs to be achieved to improve the performance of the device. Scientists have also identified that the optimization of the graphene conductivity and graphene films surface wetting has a positive effect on the performance of graphene-based electrodes. Thermal treatments (i.e., annealing) also play an important role regarding final efficiency; by this simple procedure, notable increments 
TABLE 2: PCE of BHJ OSCs using graphene as cathode.

\begin{tabular}{lccc}
\hline Material & Device conformation & Highest PCE & Reference \\
\hline MLG & MLG/WPF-6-oxy-F/P3HT $:$ PCBM/PEDOT $:$ PSS/Al & $1.23 \%$ & {$[14]$} \\
MLG & Glass/ITO/ZnO/P3HT : PCBM/MLG & $2.50 \%$ & {$[52]$} \\
SLG & ITO/PEDOT/CuPC $: \mathrm{C}_{60}:$ TPBi/SLG & $0.22 \%$ & {$[53]$} \\
rGO & PET $:$ alkali + rGO-SWCNT/P3HT $:$ PCBM/V $\mathrm{O}_{5} / \mathrm{Al}$ & $1.27 \%$ & {$[55]$} \\
SLG & Glass/ITO/ZnO/P3HT $:$ PCBM/PEDOT $:$ PSS/Au + SLG & $2.7 \%$ & {$[54]$} \\
\hline
\end{tabular}

have been achieved. In the specific case of anode-materials, graphene constitutes a viable option to substitute traditional materials, first due to its higher abundance compared to indium and second to the considerable PCE reached so far.

2.2. Cathode. Although several studies have reported on the graphene-based electrode for replacing the ITO bottom electrode in organic photovoltaic devices, the use of the graphene top electrode is still very limited [52]. The following section presents the research works related to this topic found in the scientific literature. Table 2 summarizes the best PCE achieved by devices using graphene as cathode.

Lee et al. [52] reported a simple lamination process for depositing a graphene electrode on top of a polymer photovoltaic device replacing the conventional metal electrode, resulting in a semitransparent inverted polymer solar cell with a PCE of over $75 \%$ of that of the standard opaque device using an Ag metal electrode, which was fabricated for comparison. For the preparation of the graphene top electrode, a graphene film was grown on copper foil using CVD processes. Since a single layer of graphene does not have sufficiently high sheet conductivity, multilayer stacking of the graphene film was required to obtain higher sheet conductance. The Ag-based device yielded a PCE of 3.30\% and in the best case (10-layers device) the semitransparent device achieved a PCE of $2.50 \%$ when illuminated (AM1.5, $100 \mathrm{~mW} / \mathrm{cm}^{2}$ ) from the ITO side. By contrast, while illuminated from the graphene side, the semitransparent device consisting of 8 layers of graphene exhibited an optimal PCE of $2.04 \%$ [52].

Jo et al. [14] fabricated inverted-structure OSCs with graphene cathodes. The graphene film used in this work was work function-engineered with an interfacial dipole layer to reduce the work function of graphene, which resulted in an increase in the built-in potential and enhancement of the charge extraction, thereby enhancing the overall device performance. MLG film was grown through CVD on nickel films as reported elsewhere. The work function of the untreated MLG film was $4.58 \pm 0.08 \mathrm{eV}$, which is close to the work function of highly ordered pyrolytic graphite $(4.5 \mathrm{eV})$. The work function of the MLG film was reduced by the use of different interfacial layers made of poly-ethylene oxide (PEO), poly[9,9-bis $((6$ ' $(\mathrm{N}, \mathrm{N}, \mathrm{N}$-trimethylammonium) hexyl)-2,7-fluorene)-alt-(9,9-bis(2-(2-(2-methoxyethoxy) ethoxy)ethyl)-9-fluorene)] dibromide (denoted by WPF6-oxy-F), and $\mathrm{Cs}_{2} \mathrm{CO}_{3}$. These interfacial layers formed interfacial dipoles that pointed away from the MLG surface, thereby decreasing the MLG work function. WPF-6-oxy-F was found as the best material because it reduces the effective work function of MLG to a value that is close to the LUMO of the acceptor material. Therefore, the best PCE (1.23\%) was obtained with WPF-6-oxy-F as the interfacial layer. The performance of the OSCs with MLG electrodes is expected to depend strongly on the quality and properties of the MLG film. The CVD-synthesized MLG films exhibited high sheet resistance in the range of 850 to $520 \Omega / \mathrm{sq}$, while the transmittance changed from $90 \%$ to $85 \%$ at a wavelength of $450 \mathrm{~nm}$ [14].

Cox et al. [53] demonstrated that a laminated singlelayer graphene (SLG) grown through chemical vapor deposition can be used as a cathode for organic photovoltaic devices. The PCE of graphene devices was limited by their series resistance, indicating that the preparation of graphene samples with lower sheet resistance could improve device performance. In this work, aluminum control devices were used to evaluate the performance of the graphene OSCs. The graphene devices exhibited a PCE of $0.02 \%$ and the aluminum controls showed a PCE of $0.41 \%$. The $V_{\text {oc }}$ for both types of instruments was approximately $0.45 \mathrm{~V}$. This large efficiency disparity in conjunction with similar $V_{\text {oc }}$ 's indicated that parasitic series resistance dominated the characteristics of the graphene devices. To minimize the influence of the parasitic series resistance, the devices were studied under lowintensity monochromatic illumination. At incident power of $4.6 \mathrm{~mW} / \mathrm{cm}^{2}$, the graphene device exhibits a PCE of $0.22 \%$ [53].

Liu et al. [54] reported the fabrication of a semitransparent device with a SLG synthesized on copper foils with CVD method used as top electrode. The device was optimized by tuning the active layer thickness and changing the conductance and the work function of single-layer graphene by doping Au nanoparticles and PEDOT : PSS. For each synthesis condition, three identical cells were fabricated and the average PCE was calculated. The devices were illuminated on each side under an AM1.5 solar simulator with the intensity of $100 \mathrm{~mW} / \mathrm{cm}^{2}$. The maximum PCE of the semitransparent cell was $2.7 \%$ for an active area of $20 \mathrm{~mm}^{2}$ when illuminated from the graphene side, which is much higher than the value from the ITO side (2.2\%). It was also found that the PCE of the device decreased from $3 \%$ to $2.3 \%$ with the increase of the size from 6 to $50 \mathrm{~mm}^{2}$, which was attributed to both the increased series resistance and the decreased edge effect of the device [54].

Huang et al. [55] found that the work functions $\left(\phi_{w}\right)$ of solution-processable, functional graphene/carbon nanotubebased transparent conductors were readily manipulated, 
TABLE 3: PCE of BHJ OSCs using graphene as acceptor material.

\begin{tabular}{|c|c|c|c|}
\hline Material & Device conformation & Highest PCE & Reference \\
\hline SPFGraphene & ITO/PEDOT : PSS/P3OT : SPFGraphene/LiF/Al & $1.40 \%$ & [56] \\
\hline SPFGraphene & Glass/ITO/PEDOT: PSS/P3HT: SPFGraphene/LiF/Al & $0.69 \%$ & [58] \\
\hline SPFGraphene & ITO/PEDOT : PSS/P3HT : SPFGraphene/LIF/Al & $1.10 \%$ & [64] \\
\hline SPFGraphene & Glass/ITO/PEDOT : PSS/P3HT : SPFGraphene/LiF/Al & $0.88 \%$ & [61] \\
\hline Graphene & Glass/ITO/PEDOT : PSS/P3HT : PDI-G hybrid/LiF/Al & $1.04 \%$ & [63] \\
\hline SPFGraphene & Glass/ITO/PEDOT: PSS/P3HT: SPFGraphene/LiF/Al & $1.046 \%$ & [66] \\
\hline SPFGraphene & ITO/PEDOT: PSS/P3HT: PCBM : SPFGraphene/Al & $1.40 \%$ & [67] \\
\hline Graphene & Glass/ITO/PEDOT : PSS/C $6_{60}-\mathrm{G}: \mathrm{P} 3 \mathrm{HT} / \mathrm{Al}$ & $1.22 \%$ & {$[62]$} \\
\hline BCFG-F & Glass/ITO/PEDOT: PSS/P3HT: BCFG-F/LiF/Al & $1.10 \%$ & [60] \\
\hline SPFGraphene & Glass/ITO/PEDOT : PSS/P3HT : MDMO-PPV : SPFGraphene/LiF/Al & $1.506 \%$ & [65] \\
\hline Graphene & Glass/ITO/PEDOT : PSS/P3HT : PCBM : graphene/LiF/Al & $0.70 \%$ & [59] \\
\hline
\end{tabular}

varying between 5.1 and $3.4 \mathrm{eV}$, depending on the nature of the doping alkali carbonate salt used. Highly conductive and transparent graphene-based electrodes with tunable work functions were prepared by combining single walled carbon nanotubes (SWCNTs) with chemically reduced graphene (rGO). Composite films were doped with alkali carbonates, which were decomposed into alkali oxides by means of thermal annealing that covered the carbon-based materials. Graphene-based electrodes possessing lower values of $\phi_{w}$ were used as cathodes in inverted-architecture polymer photovoltaic devices to effectively collect electrons. As expected, increasing the number of spin-layers from one to five provided thicker carbon composite films, thereby decreasing the optical transmittance at $550 \mathrm{~nm}$ from 88.8 (1 layer) to $58.7 \%$ (5 layers). Therefore, an optimal rGO-SWCNT thickness exists for optimal PV performance. The best PCE of the P3HT: PCBM photovoltaic device was achieved when incorporating the four-layer rGO-SWCNT (1.27\%) [55].

According to the results presented in the previous section, the control of the work function of graphene layers constitutes the main strategy to improve the conductivity and the overall power conversion efficiency of BHJ solar cells using graphene as cathode material. This goal may be achieved following different procedures, for example, using interfacial layers or doping graphene films with different kind of agents. Other strategies to enhance the PCE include the tuning of the active layer thickness to maximize light absorption and charge transport. Regarding the preparation of the graphene electrode, CVD is the most used route, while lamination is the most commonly method used to deposit the electrode. However, the high processing temperature required for CVD limits the growth of graphene to a restricted number of substrates, which could have a negative impact on the performance of the BHJ device. Thus, it is clear that further enhancement in the conductivity of the graphene electrode is needed and constitutes the next step in order to increase the overall performance of the cathode-graphene-based devices. In the same way, the development of alternative methods for preparing large-area graphene films is required, since massive preparation of graphene films would be needed to satisfy global demand.

\section{Active Layer Material}

The active layer of an ideal BHJ solar cell is defined as a bicontinuous interpenetrating network of donor and acceptor at the nanometer scale with maximum interfacial area. In this case, excitons can always reach the $\mathrm{D} / \mathrm{A}$ interface within their limited diffusion length and charge separation can occur efficiently. So far, the most successful active layer with $\mathrm{BHJ}$ architecture is based on either soluble $\mathrm{P} 3 \mathrm{HT}$ or poly-3-octylthiophene (P3OT) as the donor and PCBM or $\mathrm{PC}_{70} \mathrm{BM}$ (6,6-phenyl- $\mathrm{C}_{70}$-butyric acid methyl ester) as the acceptor. Solar cells based on P3HT have exhibited PCE values approaching $5 \%$, depending on the architecture of the device. On the other hand, it is known that PCBM is not the optimum acceptor material and limits the efficiency of the organic devices. Thus, new materials for both donor and acceptor with better $\mathrm{HOMO} / \mathrm{LUMO}$ matching, stronger light absorption, and higher charge mobility with good stability are much needed $[6,56,57]$. In this section, the use of graphene as acceptor material is described, and the PCE and the conformation of $\mathrm{BHJ}$ devices using graphene are summarized in Table 3.

Liu et al. [58] used graphene as the acceptor material in BHJ organic photovoltaic cells. To achieve good dispersion of graphene, a solution-processable functionalized graphene (SPFGraphene) was prepared by a two-step method consisting of an oxidation step followed by an organic functionalization step. The oxidation treatment using a modified Hummers' method of the flake gave out graphene oxide sheets having a thickness of $\sim 0.7 \mathrm{~nm}$ and a dimension of several hundreds of nanometers. Then, a phenyl isocyanate treatment gave out SPFGraphene that could be dissolved in organic solvent. The active layer was prepared by spin-coating using a P3HT/SPFGraphene solution in 1,2-dichlorobenzene (SPFGraphene content: $0 \%, 2.5 \%, 5 \%, 10 \%$, and $15 \%$ ). The current-voltage $(J-V)$ curves of the photovoltaic devices were determined using an AM1.5G standard operating with an illumination intensity of $100 \mathrm{~mW} / \mathrm{cm}^{2}$. Under illumination, the device based on pristine P3HT gave PCE of $0.005 \%$, while the P3HT/10\%-SPFGraphene based device gave a maximum PCE value of $0.15 \%$, which is much higher than that of the control device based on pristine P3HT. The authors 
also reported that after annealing at $160^{\circ} \mathrm{C}$ for $10 \mathrm{~min}$ a top PCE of $0.69 \%$ for the P3HT/5\%-SPFGraphene was registered [58].

Yu and Kuppa [59] investigated BHJ devices employing graphene nanosheets in the active layer. Solar cells based on P3HT: PCBM : graphene showed device physics significantly different from traditional $\mathrm{BHJ}$ s and displayed a monotonic increase in performance with graphene concentration. The PCE of a device based on a P3HT:PCBM blend at a $20: 2$ concentration ratio was about $0.2 \%$, while the addition of only small amounts of graphene (concentration ratio 20:2:0.01 for P3HT: PCBM : graphene) led to a better performance of about $0.7 \%$. Hence, although the introduction of graphene sheets may have had a slightly negative effect on the $V_{\mathrm{oc}}$ and FF, the subsequent improvement in charge mobility and increase in $J_{\mathrm{sc}}$ compensated more for these drawbacks and led to an increase in efficiency [59].

Ye et al. [60] grafted a benzoic acid group onto pristine graphene (BCFG, graphene functionalized with benzoic acid) to improve its solubility and open a band gap of the resultant graphene. BCFG was esterified with $1 \mathrm{H}, 1 \mathrm{H}, 2 \mathrm{H}, 2 \mathrm{H}-$ perfluoro-1-octanol to obtain BCFG-F, which was blended with P3HT to be used as the active layer in BHJ devices. Solar cells of P3HT/BCFG-F with functionalized graphene content of $5 \mathrm{wt} \%, 7.5 \mathrm{wt} \%, 10 \mathrm{wt} \%$, and $12.5 \mathrm{wt} \%$ (ratio to $\mathrm{P} 3 \mathrm{HT}$ ) were fabricated. PCEs of $0.24,0.46,1.1$, and 0.48 were obtained for these devices, respectively. In order to realize the dependence of the photovoltaic performance on the BCFG-F content, the surface morphology of the composites used as active layer was investigated. It was found that, in composite films containing $5 \mathrm{wt} \%$ of BCFG-F, only a few functionalized graphene sheets could be seen embedded in the P3HT matrix. Therefore, for low BCFG-F content, it cannot form enough P3HT/BCFG-F interfaces, at which the separation of excitons occurs, and continuous pathways in the P3HT matrix for the effective electron transport. In the composite film with $10 \mathrm{wt} \%$ BCFG-F, there were more graphene sheets than in the film with $5 \mathrm{wt} \%$ and they were well dispersed in the P3HT matrix, to form abundant P3HT/BCFG-F interfaces for charge generation and interpenetrating networks. Finally, for the film of the composite with a $15 \mathrm{wt} \%$ content, the morphology of the film demonstrated great agglomerated forms by aggregated graphene sheets, which had a deleterious effect on exciton separation and charge transport in the active layer [60].

Liu et al. [61] designed an organic photovoltaic device based on an acceptor of solution-processable functionalized graphene (SPFGraphene). The tested devices were based on heterostructure polymer- (P3HT-) graphene composite layers as active layer. Different active layers were synthetized by means of spin-coating from a solution of $15 \mathrm{mg} / \mathrm{mL}$ P3HT in chlorobenzene with SPFGraphene content of $0 \mathrm{wt} \%$, $1 \mathrm{wt} \%, 2.5 \mathrm{wt} \%$, $5 \mathrm{wt} \%, 10 \mathrm{wt} \%, 12.5 \mathrm{wt} \%$, and $15 \mathrm{wt} \%$. Doping of graphene into $\mathrm{P} 3 \mathrm{HT}$ resulted in appropriate energetic distance between HOMO and LUMO of the donor/acceptor for a high open circuit voltage and provided higher exciton dissociation volume mobility of carrier transport for a large short-circuit current density. The device containing only $10 \mathrm{wt} \%$ of graphene showed the best PCE $(0.88 \%)$, an open circuit voltage of $0.77 \mathrm{~V}$, and a short-circuit current density of $3.72 \mathrm{~mA} / \mathrm{cm}^{2}$. SPFGraphene content was the main factor improving PCE. For smaller concentrations, such as $1 \mathrm{wt} \%$ and $2.5 \mathrm{wt} \%$, the SPFGraphene film was too small to form a continuous donor/acceptor interface and the transport pathway for the active layer P3HT matrix. Therefore, the electron cannot effectively meet the donor/acceptor interface and transport smoothly through the active layer. However, if SPFGraphene is further increased to a concentration of $10 \mathrm{wt} \%$, the SPFGraphene film can form a continuous donor/acceptor interface and produce a better way to be transported smoothly through $\mathrm{P} 3 \mathrm{HT}$ matrix, improving the electronic transport. However, if there is a further increase in the concentration of SPFGraphene, such as $12.5 \mathrm{wt} \%$ and $15 \mathrm{wt} \%$, then the aggregation of SPFGraphene occurred, reducing hole mobility and decreasing the number of extracted carriers [61].

Yu et al. [62] developed a lithiation reaction to covalently attach monosubstituted fullerene $\left(\mathrm{C}_{60}\right)$ onto graphene $(\mathrm{G})$ nanosheets to be used as electron acceptors in P3HT-based $\mathrm{BHJ}$ solar cells. Graphene nanosheets were produced through reduction of $\mathrm{GO}$ in pure hydrazine and purified with toluene and methanol. Using $\mathrm{C}_{60}-\mathrm{G}: \mathrm{P} 3 \mathrm{HT}$ (1:1wt/wt), $\mathrm{C}_{60}: \mathrm{P} 3 \mathrm{HT}$ (1:1wt/wt), and $\mathrm{C}_{60} / \mathrm{G}$ mixture (i.e., $12 \mathrm{wt} \%$ graphene, physical blend without chemical functionalization): $\mathrm{P} 3 \mathrm{HT}$ $(1: 1 \mathrm{wt} / \mathrm{wt})$ as a control, the device performance of a series of $\mathrm{BHJ}$ solar cells using such materials as active layer was tested under AM1.5 illumination. A PCE of $0.47 \%$ was obtained for the $\mathrm{C}_{60}:$ P3HT system, while the $\mathrm{C}_{60}-\mathrm{G}: \mathrm{P} 3 \mathrm{HT}$ system showed a PCE of $1.22 \%$. The observed enhancement could be attributed to the improved electron transport due to the presence of the $\mathrm{C}_{60}$-grafted graphene. In the case of the $\mathrm{C}_{60}$ : graphene device, the simple blending of $\mathrm{C}_{60}$ with the graphene cannot ensure a good interfacial contact to facilitate strong electronic interactions for efficient electron transport between the two components. To make it even worse, graphene sheets easily aggregated in the composite film, due to poor miscibility, to show a detrimental effect on the charge separation/transport. Therefore, the overall device efficiency was not improved (0.44\%) [62].

Liu et al. [56] reported the fabrication and performance of devices with BHJ structure using an organic SPFGraphene as electron-acceptor material and P3OT (poly(3-octylthiophene 2,5 diyl)) and P3HT as donor material. Devices with SPFGraphene content of $1 \mathrm{wt} \%, 5 \mathrm{wt} \%$, and $15 \mathrm{wt} \%$ (ratio to $\mathrm{P} 3 \mathrm{OT}$ ) were fabricated. The authors indicated that the functionalized graphene material could be dispersed into organic solvent to form a homogeneous solution. Controlled annealing improved the device performance, and the best PCE of $1.4 \%$ (5 wt\% SPFGraphene) was obtained using simulated $100 \mathrm{~mW} / \mathrm{cm}^{2}$ AM1.5G illumination after annealing during $20 \mathrm{~min}$ at $160^{\circ} \mathrm{C}$. Although the reported PCE is moderate, it is comparable with most of the best devices using materials other than fullerenes as electron acceptors. Furthermore, there is much room for improvement, such as optimizing the graphene content, annealing temperature, and time further controlling the size and functionalized degree of graphene sheets and the device fabrication and structure [56]. 
Wang et al. [63] studied the role of graphene (rGO) as atomic and structural scaffold in the nucleation and assembly of organic nanostructures. The photovoltaic properties of the PDI ( $N, N^{\prime}$-dioctyl-3,4,9,10-perylenedicarboximide) and graphene hybrids were investigated to determine whether they offer enhanced performances over those of the individual constituents like PDI and G. PDI-G hybrids were prepared by the hydrothermal treatment of GO and PDI in DMF. The authors also investigated the performance of physically mixed PDI + G composites made of PDI and G; this system was used as a control to compare with the PDI-G hybrid wires in order to find out if the coating of $G$ around the PDI wires offers any enhanced performance. Using BHJ cells tested under $100 \mathrm{~mW} / \mathrm{cm}^{2}$ AM1.5 illumination, it was found that PDI-G hybrid wires based cells showed a PCE of 1.04\%, while PDI cells presented a PCE of only $0.064 \%$ [63].

Liu et al. [64] studied a BHJ device with an active layer consisting of P3HT and SPFGraphene. According to their results, adding graphene to the $\mathrm{P} 3 \mathrm{HT}$ induced a great quenching of the photoluminescence of the $\mathrm{P} 3 \mathrm{HT}$, indicating a strong electron/energy transfer from the P3HT to the graphene. The device containing only $10 \mathrm{wt} \%$ of graphene showed the best performance with a PCE of $1.1 \%$ under simulated AM1.5G conditions at $100 \mathrm{~mW} / \mathrm{cm}^{2}$ after an annealing treatment at $160^{\circ} \mathrm{C}$ for $10 \mathrm{~min}$. The annealing treatment at $160^{\circ} \mathrm{C}$ greatly improved the device performance. However, overgenerous conditions such as those at $210^{\circ} \mathrm{C}$ resulted in a decrease in the device efficiency $(0.57 \%)$ [64].

Wang et al. [65] reported on the fabrication of $\mathrm{BHJ}$ devices based on P3HT: SPFGraphene doped with poly-2methoxy-5-(30,70-dimethyloctyloxy)-1,4-phenylenevinylene (MDMO-PPV) and P3OT. In this work, the amount of MDMO-PPV incorporated to the P3HT:SPFGraphene active layer was varied from 0 to $2 \mathrm{mg}$, while the amount of $\mathrm{P} 3 \mathrm{OT}$ varied in the range from 0 to $3 \mathrm{mg}$. For further characterization, the solar cells were illuminated through the side of the ITO-coated glass plate. AM1.5G standard operating with an illuminated intensity of $100 \mathrm{~mW}$ xenon lamp was used as a broadband light source. The authors pointed out that nondoped P3HT:SPFGraphene showed an efficiency of $1.046 \%$. By incorporating different amounts of P3OT, the best efficiency obtained was of $1.12 \%$ when $1 \mathrm{mg}$ of P3OT was added. On the other hand, a top efficiency of $1.506 \%$ was registered when $1.5 \mathrm{mg}$ of MDMO-PPV was used [65].

Wang et al. [66] fabricated solar cell devices based on SPFGraphene oxide and P3HT with different contents of SPFGraphene oxide $(0 \%, 2.5 \%, 5 \%, 7.5 \%, 10 \%, 12.5 \%$, and $15 \%)$. The $\pi$-conjugation of graphene enables the polymers to be used as an active material for various functional devices, including photovoltaic devices. The pure P3HT thin film showed strong photoluminescence between 600 and $800 \mathrm{~nm}$ with excitation at $450 \mathrm{~nm}$; however, the photoluminescence is remarkably reduced after doping of SPFGraphene oxide, showing that efficient energy transfer occurred along the P3HT/SPFGraphene oxide interface. The overall performance of the P3HT/SPFGraphene oxide based devices was much higher than that of the pristine P3HT-based one. The improved photovoltaic performance was attributed to the addition of the SPFGraphene oxide, stating that there is an obvious charge transfer from the P3HT donor to the SPFGraphene oxide acceptor. To recover the conjugated structure and conductivity of the graphene sheet through removing the organic functional groups from the SPFGraphene oxide sheet, a thermal annealing process was carried out at $160^{\circ} \mathrm{C}$ at different times. The best PCE was obtained for a device containing $10 \mathrm{wt} \%$ of SPFGraphene annealed during $10 \mathrm{~min}$ (1.046\%) [66].

Liu et al. [67] tested a SPFGraphene in P3HT/PCBM photovoltaic devices. Tested devices took advantage of the electron-accepting feature of fullerenes and the high electron transport capability of graphene. The photovoltaic performance was investigated for devices containing $0 \%, 1 \%, 2.5 \%$, $5 \%, 10 \%, 12.5 \%$, and $15 \%$ of graphene. The best results were obtained with P3HT:PCBM (1:1) mixture with $10 \mathrm{wt} \%$ of graphene with a PCE of $1.4 \%$ at illumination at $100 \mathrm{~mW} / \mathrm{cm}^{2}$ AM1.5. Results indicated that the addition of graphene enhanced the performance of polymer photovoltaic devices [67].

Different methods to obtain graphene-based materials have been developed (e.g., adhesive tape, epitaxial growth, and micromechanical cleavage). However, most of these methods are not suitable for low-cost, large-area optoelectronics. In this tenor, organic solution-processable materials are preferred for electronic applications due to their solubility using common solvents, which allow them to be used in polymer-composite based materials preparation. Solutionprocessable functionalized graphene (SPFGraphene) is by far the most used functionalized graphene-based (Figure 4) material employed in the development of $\mathrm{BHJ}$ devices. Although the performance of the cells using this material is lower than the most efficient BHJ cells tested, it is clear that the use of graphene significantly increases the efficiency compared to the reference devices (i.e., without graphene) reported in each experiment. The key to improve the PCE of SPFGraphene based materials seems to be related to the improvement of its miscibility, which will assure a good dispersion of the graphene in the polymer matrix. A better miscibility will also avoid agglomeration and its detrimental effects on charge separation/transport. Thus, in this way, the hole mobility and the number of extracted carriers will be increased. An improved solubility will also ensure a good interfacial contact to facilitate strong electronic interactions for a better charge generation. Another important factor to be considered is the graphene content that needs to be enough to form a continuous donor/acceptor interface and an efficient transport pathway for the active layer. Finally, annealing has proved to be an efficient treatment to increase power conversion efficiency since it considerably increases the $V_{\text {oc }}$ of the device.

\section{Transport/Extraction Layer Material}

The interfaces between active layer and anode and cathode play an essential role in determining the overall device performance of organic electronics [68]. In a simple BHJ device, both the donor and acceptor phases are in direct 
TABLE 4: PCE of BHJ OSCs using graphene as HTLs and EELs.

\begin{tabular}{|c|c|c|c|c|}
\hline Material & Function & Device conformation & Highest PCE & Reference \\
\hline GO & HTLs & ITO/GO/P3HT : PCBM/Al & $3.50 \%$ & {$[78]$} \\
\hline GO & HTLs & ITO/PEDOT : PSS : GO/P3HT : PCBM/LiF/Al & $3.80 \%$ & [86] \\
\hline GO & HTLs & ITO/GO $: \mathrm{NiO}_{x} / \mathrm{P} 3 \mathrm{HT}: \mathrm{PCBM} / \mathrm{LiF} / \mathrm{Al}$ & $3.48 \%$ & [79] \\
\hline FLGs & HTLs & Glass/ITO/FLGs-PEDOT: PSS/P3HT : PCBM/Ca/Al & $3.70 \%$ & {$[85]$} \\
\hline mrGO & HTLs & Glass/ITO/mrGO/P3HT : PCBM/LiF/Al & $3.98 \%$ & [81] \\
\hline $\mathrm{GO}-\mathrm{OSO}_{3} \mathrm{H}$ & HTLs & $\mathrm{ITO} / \mathrm{GO}-\mathrm{OSO}_{3} \mathrm{H} / \mathrm{P} 3 \mathrm{HT}: \mathrm{PCBM} / \mathrm{Ca} / \mathrm{Al}$ & $4.37 \%$ & {$[82]$} \\
\hline GO & HTLs & ITO/GO/P3HT : PCBM/LiF/Al & $3.25 \%$ & \\
\hline GO-Cs & EELs & ITO/PEDOT : PSS/P3HT : PCBM/GO-Cs/Al & $3.08 \%$ & [83] \\
\hline GO/GO-Cs & HTLs/EELs & ITO/GO/P3HT : PCBM/GO-Cs/Al & $3.67 \%$ & \\
\hline UV/ozone-G & HTLs & ITO/UV/ozone-G/P3HT : PCBM/LiF/Al & $3.00 \%$ & {$[80]$} \\
\hline rGO & EELs & Glass/ITO/PEDOT : PSS/P3HT: PCBM/rGO-pyrene : PCBM/Al & $3.89 \%$ & [84] \\
\hline
\end{tabular}

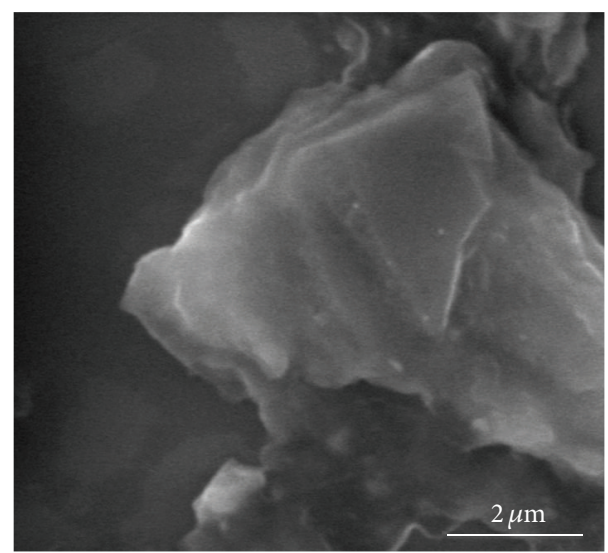

FIGURE 4: SEM micrograph of SPFGraphene.

electrical contact with the cathode and anode electrodes, leading to recombination of carriers and current leakage. To minimize such detrimental effects, hole transport layers (HTLs) and electron extraction layers (EELs) are used. HTLs must be wide band gap p-type materials; in this respect, several inorganic transition metal oxides such as molybdenum, nickel, rhenium, vanadium, or tungsten oxides $\left(\mathrm{V}_{2} \mathrm{O}_{5}, \mathrm{ReO}_{3}, \mathrm{WO}_{3}\right.$, and $\mathrm{MoO}_{3}$ with $\mathrm{NiO}$ being the most effective) have been reported yielding efficiencies greater than $5 \%$. In a detrimental manner, inorganic HTLs are deposited using vacuum deposition methods that are incompatible with solution-processable printable electronic techniques used to fabricate photovoltaic devices [69-71].

The most commonly employed material used as HTLs in polymer solar cells is semiconducting PEDOT:PSS, which is used between the ITO anode and the active layer. PEDOT: PSS has the advantages of being deposited from solution and serve to minimize the detrimental effects of ITO roughness and to align the work function of $\mathrm{P} 3 \mathrm{HT}$ and ITO for more efficient collection of holes. However, it is usually deposited from highly acidic aqueous suspensions that are known to corrode ITO at elevated temperatures and can also introduce water into the active layer, degrading the device performance $[68,72,73]$.
On the other hand, certain metal fluorides, n-type semiconductors (e.g., $\mathrm{TiO}_{2}, \mathrm{TiO}_{x}$, and $\mathrm{ZnO}$ ), n-type organic semiconductors (e.g., 2,9-dimethyl-4,7-diphenyl-1,10-phenanthroline, BCP), and conjugated polymer electrolytes have been used as the EELs [74-77]. Materials used as EELs need to have a low work function for electrons to be efficiently transported to the cathode.

Thus, several research groups, motivated by the need to overcome the limitations of PEDOT : PSS as the conventional HTLs by finding a suitable solution-processable alternative that is compatible with OSCs materials and fabrication techniques and by the need to find new materials to serve as both HTLs and EELs that could not only simplify the materials design and device fabrication but also allow for a precise control of the energy barrier for electron and hole extraction by tuning its work function via, for example, controlled functionalization, have reported their findings, which are summarized in the following section and in Table 4 .

Li et al. [78] used graphene oxide thin films as the hole transport and electron extraction layer in OSCs. To evaluate the performance of GO devices, a set of two other devices was fabricated for comparison. One set was ITOonly control devices, and the other was the conventional OSCs incorporating PEDOT: PSS as the hole transport layer. The photovoltaic characteristics of the fabricated devices were characterized under simulated AM1.5 illumination at $100 \mathrm{~mW} / \mathrm{cm}^{2}$. ITO-only device exhibited an average PCE of $1.8 \%$. The insertion of a $2 \mathrm{~nm}$ thick GO thin film between ITO and P3HT : PCBM led to an enhancement in the PCE to $3.5 \%$, while the typical PEDOT : PSS typical device had shown a 3.6\% PCE. Thus, the incorporation of GO deposited from neutral solutions between the photoactive P3HT:PCBM layer and the transparent and conducting ITO led to a decrease in recombination of electrons and holes and leakage currents, resulting in a dramatic increase in the device PCE to values that are comparable to devices fabricated with PEDOT : PSS as the hole transport layer. [78].

Ryu and Jang [79] reported a solution processed GO, $\mathrm{NiO}_{x}$, and $\mathrm{GO} / \mathrm{NiO}_{x}$ bilayer used as an anode interfacial layer in a $\mathrm{BHJ}$ device. In order to obtain the optimized thickness of GO layer, cells with different numbers of GO layers were fabricated by spin-coating. The best cell performance was 
achieved for the cell with 3 GO layers, exhibiting a PCE of $2.75 \%$, which was superior to that of the cell without HTL $(2.33 \%)$. On the other hand, the device with a solution processed $\mathrm{NiO}_{x}$ layer showed an improved PCE of $3.10 \%$. To further enhance cell performance of the device with GO and $\mathrm{NiO}_{x}$, devices with $\mathrm{GO} / \mathrm{NiO}_{x}$ and $\mathrm{NiO}_{x} / \mathrm{GO}$ were fabricated. Cell performance of the OSC with $\mathrm{NiO}_{x} / \mathrm{GO}$ as HTLs was similar to the device with a $\mathrm{NiO}_{x}$. However, the device with a $\mathrm{GO} / \mathrm{NiO}_{x}$ layer showed an enhanced cell performance, indicating a $15 \%$ increase in PCE, compared to the cell without HTL. These results indicated that the $\mathrm{NiO}_{x}$ functions both as a hole transport and an electron extraction layer. The device with a $\mathrm{GO} / \mathrm{NiO}_{x}$ showed a PCE of $3.48 \%$. The cell efficiency is correlated with the matching of energy levels between ITO, hole transport layer, and $\mathrm{P} 3 \mathrm{HT}$ and thus a wellmatched $\mathrm{GO} / \mathrm{NiO}_{x}$ showed the best PCE [79].

Kwon et al. [80] fabricated organic devices using UV/ ozone-treated graphene sheets as HTLs. A PEDOT: PSScoated ITO device was used as reference and, in the case of the UV/ozone-treated graphene devices, the graphene was transferred onto the ITO glass following exposure to UVozone with a power of $30 \mathrm{~mW} / \mathrm{cm}^{2}$ for $1,3,5,7$, and $9 \mathrm{~min}$. Cells were tested under AM1.5G $100 \mathrm{~mW} / \mathrm{cm}^{2}$ illumination. In the best case (UV-ozone treated device for $9 \mathrm{~min}$ ), the sheet resistance increased from $1.1 \mathrm{k} \Omega / \mathrm{sq}$ to infinity and the transmittance at $550 \mathrm{~nm}$ decreased from $95.2 \%$ to $93.8 \%$ due to the formation of carbon-oxygen functionalization layers. Although the device with $9 \mathrm{~min}$ treated graphene was expected to show the best efficiency (PCE of 1.46\%) due to its highest work function $(4.85 \mathrm{eV})$, the best PCE was obtained from the cell with $5 \mathrm{~min}$ treated graphene $(3.00 \%)$ probably because the graphene sheet was damaged by UVozone exposure after $7 \mathrm{~min}$, which roughened the surface creating defects [80].

Jeon et al. [81] used moderately reduced graphene oxide (mrGO) as an alternative to the PEDOT: PSS HTL in BHJ OSCs. mrGO films were fabricated by simple and fast thermal treatment of solution processed mrGO. Spin-coated mrGO layers were thermally treated at 150,250 , and $350^{\circ} \mathrm{C}$ for $10 \mathrm{~min}$ in air. Devices without and with thermal treatment at 150 and $250^{\circ} \mathrm{C}$ showed a well-formed 2-dimensional nanosheet. On the other hand, in the case of mrGO films thermally treated at $350^{\circ} \mathrm{C}$, some aggregation of nanosheets and relatively nonuniform morphologies were observed. The thicknesses of nanosheets of mrGO without and with thermal treatment at 150,250 , and $350^{\circ} \mathrm{C}$ were estimated to $1.18,1.07,0.87$, and $0.85 \mathrm{~nm}$, respectively. The decrease in the thickness of single sheet resulted from the removal of oxygen groups, indicating that solution processed mfGO films were reduced by simple thermal treatment. Devices with thermally treated $\mathrm{mrGO}$ at $250^{\circ} \mathrm{C}$ exhibited the best PCE (3.98\%) compared to devices containing conventional PEDOT: PSS HTLs, which showed $3.85 \%$. Furthermore, mrGO-based cells showed superior stability compared to conventional devices under atmosphere condition without any encapsulation process [81].

Liu et al. [82] developed a sulfated graphene oxide (GO$\mathrm{OSO}_{3} \mathrm{H}$ ) with $-\mathrm{OSO}_{3} \mathrm{H}$ groups attached to the carbon basal plane of reduced GO surrounded with edge-functionalized
$-\mathrm{COOH}$ groups to be used as HTLs. Different devices based on $\mathrm{GO}$ and $\mathrm{GO}-\mathrm{OSO}_{3} \mathrm{H}$ were fabricated varying the thickness of the HTLs from 2 to $6 \mathrm{~nm}$. The best results were obtained when using $2 \mathrm{~nm}$ thick HTLs. Because of the poor conductivity of GO, an increase in the GO thickness from 2 to $6 \mathrm{~nm}$ increased the series from 3.1 to $6.4 \Omega \mathrm{cm}^{2}$ and hence decreased the PCE. By contrast, the performance of the $\mathrm{GO}-\mathrm{OSO}_{3} \mathrm{H}$-based devices is nearly independent of the HTLs thickness over the range from 2 to $6 \mathrm{~nm}$. Compared to that of GO, the better conductivity of $\mathrm{GO}-\mathrm{OSO}_{3} \mathrm{H}$ led to an improved PCE of $4.37 \%$ versus $3.34 \%$ of GO. The control devices based on PEDOT : PSS exhibited a PCE of $4.39 \%$. The relatively poor photovoltaic performance observed for the GO device can be attributed to high series resistance associated with the insulating GO. Compared with the GO-based devices, their $\mathrm{GO}-\mathrm{OSO}_{3} \mathrm{H}$ counterparts exhibited a much lower series resistance and hence a significantly improved PCE [82].

Liu et al. [83] reported on the functionalization of GO to produce both hole and electron extraction materials for $\mathrm{BHJ}$ solar cells. GO was tested as HTLs and GO-Cs, in which the periphery - $\mathrm{COOH}$ groups in $\mathrm{GO}$ were replaced by -COOCs, as EELs. GO itself has a work function of $4.7 \mathrm{eV}$, which matches the HOMO level of P3HT for hole extraction. By replacing the periphery $-\mathrm{COOH}$ with the $-\mathrm{COOCs}$ groups through charge neutralization, the work function of the GOCs can be reduced to $4.0 \mathrm{eV}$, which matches the LUMO level of PCBM for efficient electron extraction. To investigate the hole extraction ability of GO, three different devices with the same active layer, cathode, and EELs were compared. The device with GO as HTLs showed a PCE of $3.25 \%$, which was superior to that of the device using PEDOT: PSS (3.15\%), implying that GO is an excellent hole extraction material for $\mathrm{BHJ}$ solar cells. Similarly, to evaluate the ability of GO-Cs as the electron extraction layer, four devices were fabricated with the same anode, hole extraction layer, active layer, and cathode. In this case, the device using LiF showed the best PCE (3.15\%). However, the cell based on GO-Cs exhibited a fairly comparable PCE (3.08\%) showing the great capability of GO-Cs as electron extraction material in BHJ solar cells. Finally, based on the excellent capabilities demonstrated for $\mathrm{GO}$ and GO-Cs, a pair of $\mathrm{BHJ}$ devices with both materials was fabricated. For this purpose, both the normal and inverted configurations were investigated. In both cases, the devices exhibited a better performance (3.67\% and $2.97 \%$, resp.) than that of the control device $(1.20 \%)$ based on $\mathrm{Cs}_{2} \mathrm{CO}_{3}$ and PEDOT: PSS [83].

$\mathrm{Qu}$ et al. [84] reported a graphene fullerene composite (rGO-pyrene-PCBM), in which PCBM was attached onto $\mathrm{rGO}$ via the noncovalent functionalization approach. rGO-pyrene-PCBM was successfully applied as EELs for P3HT : PCBM BHJ devices, affording a PCE of $3.89 \%$, which is enhanced by $\sim 15 \%$ compared to that of the reference device without EELs (3.39\%). Additionally, the comparative devices incorporating the rGO or pyrene-PCBM component as EELs showed dramatically decreased PCE, $2.53 \%$ and $2.18 \%$, respectively, which are much lower than that of the reference device, indicating the importance of composite 
formation between $\mathrm{rGO}$ and pyrene-PCBM components for its electron extraction property [84].

Nguyen et al. [85] demonstrated the use of a few-layered graphene nanosheets- (FLGs-) PEDOT: PSS composite as an effective HTL that improves the hole transporting ability in an organic device, with which the PCE was enhanced from $3.10 \%$ to $3.70 \%$. FLGs are considered to be a class of graphene materials, namely, 2D graphitic crystals, with extraordinary electronic transport properties varied systematically by the number of graphene layers. FLGs were synthetized via exfoliation from expanded graphite, since this method produces a low defects material with an excellent conductivity. To demonstrate the application of the FLGsPEDOT: PSS composite as HTLs, FLGs and PEDOT:PSS were mixed at different volume ratios $(1 / 1,2 / 1$, ) as a part of a $\mathrm{BHJ}$ device based on $\mathrm{P} 3 \mathrm{HT}$ : PCBM. All samples were measured under light illumination of AM1.5 $\left(100 \mathrm{~mW} / \mathrm{cm}^{2}\right)$. By increasing the $\mathrm{v} / \mathrm{v}$ ratio of FLGs and PEDOT: PSS, PCE increased to $3.47 \%(1 / 1)$ and $3.70 \%(2 / 1)$. Due to partially containing oxygen groups on the graphene edges of FLGs, it was expected that the work function of the FLGs was in the range of $4.4 \mathrm{eV}$ (graphite) to $5.1 \mathrm{eV}$ (acid-oxidized MWCNTs), therefore possessing an energy level close to that of P3HT. Furthermore, no significant differences were found in surface roughness between the pure PEDOT: PSS and the FLGs-PEDOT: PSS composite films, indicating that the contact resistance between the active layer and the hole transport layer was unchanged in all devices. As a result, the significant improvement of current density is attributed to higher hole mobility of FLGs as compared with PEDOT : PSS [85].

Yin et al. [86] reported a high-efficiency device made with hydrophilic GO doped in PEDOT : PSS composites used as HTLs. The PCE of the nondoped composites was of $2.1 \%$ and increased to $3.8 \%$ for the doped composites under AM1.5G $100 \mathrm{~mW} / \mathrm{cm}^{2}$ illumination in air. Preannealing of GO made PCE 1.8 times that of the device based on PEDOT: PSS. The low price and ease of preparation make soluble graphene a promising layer to be used in photovoltaic applications [86].

GO-based materials are the most used replacement for PEDOT:PSS, which is the most commonly used hole transport layer material despite its highly acidic nature and hygroscopic properties which leads to a poor long term stability of the device. A major advantage of GO-based materials relies on the fact that they can be deposited from neutral aqueous suspensions and yield efficiency values that are comparable to devices fabricated with PEDOT:PSS, not to mention that the term stability of the device is not compromised using this type of suspensions. On the other hand, the removal of oxygen from the structure of GO induces the transition of GO from an electrical insulator to a semiconductor. Thus, strategies to obtain functionalized GO using reagents with low toxicity constitute one of the main trends in this field research. Regarding EELs materials, the main goal seems to be to obtain low work function highly conductive materials to improve electrons mobility, which can achieve doping graphene with different chemical agents.

\section{Conclusions}

In this report, the various applications of graphene as a constituent of $\mathrm{BHJ}$ OSCs were discussed focusing on the PCE achieved by the graphene-based devices. Results indicate that there is a great room and need for the improvement of $\mathrm{BHJ}$ devices to compete with inorganic cells. However, there is also evidence that graphene and its derivatives can be successfully used as a main component of the different layers that constitute OSCs, giving the possibility to reduce the dependence on the materials traditionally employed. As for transparent electrode material, graphene has demonstrated great potential without the detrimental aspects of its traditional analogues; the main key to achieve a better performance relies on increasing the transparency and decreasing the sheet resistance of the graphene films. As for cathode material, the main aim is to control the work function mainly using interfacial layers or doping graphene films. Furthermore, its outstanding properties such as its band structure and dispersion ability have made it also adequate to be used as an acceptor material. The improvement of graphene miscibility to assure a good dispersion represents an important issue in order to increase the performance of the devices using graphene as a main constituent of the active layer. Additionally, its excellent charge extraction performance has made it viable to be used as transport/extraction material in $\mathrm{BHJ}$ cells. The main goal in this area is to obtain HTL-materials that can be deposited from neutral aqueous suspensions and highly conductive EEL-materials using different functionalization agents.

\section{Conflict of Interests}

The authors declare that there is no conflict of interests regarding the publication of this paper.

\section{References}

[1] B. C. Thompson and J. M. J. Fréchet, "Polymer-fullerene composite solar cells," Angewandte Chemie-International Edition, vol. 47, no. 1, pp. 58-77, 2008.

[2] X. Wan, G. Long, L. Huang, and Y. Chen, "Graphene-a promising material for organic photovoltaic cells," Advanced Materials, vol. 23, no. 45, pp. 5342-5358, 2011.

[3] T. L. Benanti and D. Venkataraman, "Organic solar cells: an overview focusing on active layer morphology," Photosynthesis Research, vol. 87, no. 1, pp. 73-81, 2006.

[4] M. Jørgensen, J. E. Carlé, R. R. Søndergaard et al., “The state of organic solar cells-a meta analysis," Solar Energy Materials and Solar Cells, vol. 119, pp. 84-93, 2013.

[5] Z. Abdin, M. A. Alim, R. Saidur et al., "Solar energy harvesting with the application of nanotechnology," Renewable and Sustainable Energy Reviews, vol. 26, pp. 837-852, 2013.

[6] E. Bundgaard and F. C. Krebs, "Low band gap polymers for organic photovoltaics," Solar Energy Materials and Solar Cells, vol. 91, no. 11, pp. 954-985, 2007.

[7] N. Yeh and P. Yeh, "Organic solar cells: their developments and potentials," Renewable and Sustainable Energy Reviews, vol. 21, pp. 421-431, 2013.

[8] A. K. Geim, “Graphene: status and prospects," Science, vol. 324, no. 5934, pp. 1530-1534, 2009. 
[9] M. Yang, Y. Hou, and N. A. Kotov, "Graphene-based multilayers: critical evaluation of materials assembly techniques," Nano Today, vol. 7, no. 5, pp. 430-447, 2012.

[10] Z. Liu, D. He, Y. Wang, H. Wu, J. Wang, and H. Wang, "Improving photovoltaic properties by incorporating both SPFGraphene and functionalized multiwalled carbon nanotubes," Solar Energy Materials and Solar Cells, vol. 94, no. 12, pp. 21482153, 2010.

[11] S. Stankovich, D. A. Dikin, G. H. B. Dommett et al., "Graphenebased composite materials," Nature, vol. 442, no. 7100, pp. 282286, 2006.

[12] G. Jo, M. Choe, C.-Y. Cho et al., "Large-scale patterned multilayer graphene films as transparent conducting electrodes for GaN light-emitting diodes," Nanotechnology, vol. 21, no. 17, Article ID 175201, 2010.

[13] Y. Zhu, S. Murali, W. Cai et al., "Graphene and graphene oxide: synthesis, properties, and applications," Advanced Materials, vol. 22, no. 35, pp. 3906-3924, 2010.

[14] G. Jo, S. Na, S. Oh et al., "Tuning of a graphene-electrode work function to enhance the efficiency of organic bulk heterojunction photovoltaic cells with an inverted structure," Applied Physics Letters, vol. 97, no. 21, pp. 213301-213303, 2010.

[15] G. V. Dubacheva, C.-K. Liang, and D. M. Bassani, "Functional monolayers from carbon nanostructures-fullerenes, carbon nanotubes, and graphene-as novel materials for solar energy conversion," Coordination Chemistry Reviews, vol. 256, no. 2122, pp. 2628-2639, 2012.

[16] A. Iwan and A. Chuchmała, "Perspectives of applied graphene: polymer solar cells," Progress in Polymer Science, vol. 37, no. 12, pp. 1805-1828, 2012.

[17] X. Du, I. Skachko, A. Barker, and E. Y. Andrei, "Approaching ballistic transport in suspended graphene," Nature Nanotechnology, vol. 3, no. 8, pp. 491-495, 2008.

[18] X. Wan, Y. Huang, and Y. Chen, "Focusing on energy and optoelectronic applications: a journey for graphene and graphene oxide at large scale," Accounts of Chemical Research, vol. 45, no. 4, pp. 598-607, 2012.

[19] R. Sengupta, M. Bhattacharya, S. Bandyopadhyay, and A. K. Bhowmick, "A review on the mechanical and electrical properties of graphite and modified graphite reinforced polymer composites," Progress in Polymer Science, vol. 36, no. 5, pp. 638670, 2011.

[20] M. Eizenberg and J. M. Blakely, "Carbon monolayer phase condensation on $\mathrm{Ni}(111)$," Surface Science, vol. 82, no. 1, pp. 228236, 1979.

[21] T. Aizawa, R. Souda, S. Otani, Y. Ishizawa, and C. Oshima, "Anomalous bond of monolayer graphite on transition-metal carbide surfaces," Physical Review Letters, vol. 64, no. 7, pp. 768771, 1990 .

[22] K. S. Novoselov, A. K. Geim, S. V. Morozov et al., "Electric field in atomically thin carbon films," Science, vol. 306, no. 5696, pp. 666-669, 2004.

[23] C. Berger, Z. Song, X. Li et al., "Electronic confinement and coherence in patterned epitaxial graphene," Science, vol. 312, no. 5777, pp. 1191-1196, 2006.

[24] S. J. Park and R. S. Ruoff, "Chemical methods for the production of graphenes," Nature Nanotechnology, vol. 4, no. 4, pp. 217-224, 2009.

[25] P. Steurer, R. Wissert, R. Thomann, and R. Mülhaupt, "Functionalized graphenes and thermoplastic nanocomposites based upon expanded graphite oxide," Macromolecular Rapid Communications, vol. 30, no. 4-5, pp. 316-327, 2009.
[26] H. C. Schniepp, J.-L. Li, M. J. McAllister et al., "Functionalized single graphene sheets derived from splitting graphite oxide," The Journal of Physical Chemistry B, vol. 110, no. 17, pp. 85358539, 2006.

[27] M. J. McAllister, J.-L. Li, D. H. Adamson et al., "Single sheet functionalized graphene by oxidation and thermal expansion of graphite," Chemistry of Materials, vol. 19, no. 18, pp. 4396-4404, 2007.

[28] J.-M. Yun, J.-S. Yeo, J. Kim et al., "Solution-processable reduced graphene oxide as a novel alternative to PEDOT:PSS hole transport layers for highly efficient and stable polymer solar cells," Advanced Materials, vol. 23, no. 42, pp. 4923-4928, 2011.

[29] V. Yong and J. M. Tour, "Theoretical efficiency of nanostructured graphene-based photovoltaics," Small, vol. 6, no. 2, pp. 313-318, 2010.

[30] T. Winzer, A. Knorr, and E. Malic, "Carrier multiplication in graphene," Nano Letters, vol. 10, no. 12, pp. 4839-4843, 2010.

[31] P. V. Kamat, "Graphene-based nanoarchitectures. Anchoring semiconductor and metal nanoparticles on a two-dimensional carbon support," Journal of Physical Chemistry Letters, vol. 1, no. 2, pp. 520-527, 2010.

[32] Y. H. Hu, H. Wang, and B. Hu, "Thinnest two-dimensional nanomaterial-graphene for solar energy," Chem Sus Chem, vol. 3, no. 7, pp. 782-796, 2010.

[33] S. Bae, H. Kim, Y. Lee et al., "Roll-to-roll production of 30-inch graphene films for transparent electrodes," Nature Nanotechnology, vol. 5, no. 8, pp. 574-578, 2010.

[34] Z. Yin, S. Sun, T. Salim et al., "Organic photovoltaic devices using highly flexible reduced graphene oxide films as transparent electrodes," ACS Nano, vol. 4, no. 9, pp. 5263-5268, 2010.

[35] J. Wu, H. A. Becerril, Z. Bao, Z. Liu, Y. Chen, and P. Peumans, "Organic solar cells with solution-processed graphene transparent electrodes," Applied Physics Letters, vol. 92, Article ID 263302, 2008.

[36] Y. Wang, S. W. Tong, X. F. Xu, B. Özyilmaz, and K. P. Loh, "Interface engineering of layer-by-layer stacked graphene anodes for high-performance organic solar cells," Advanced Materials, vol. 23, no. 13, pp. 1514-1518, 2011.

[37] F. C. Krebs, M. Jørgensen, K. Norrman et al., "A complete process for production of flexible large area polymer solar cells entirely using screen printing-First public demonstration," Solar Energy Materials and Solar Cells, vol. 93, no. 4, pp. 422-441, 2009.

[38] R. R. Nair, P. Blake, A. N. Grigorenko et al., "Fine structure constant defines visual transparency of graphene," Science, vol. 320, no. 5881, p. 1308, 2008.

[39] Y. Zhang, Y.-W. Tan, H. L. Stormer, and P. Kim, "Experimental observation of the quantum Hall effect and Berry's phase in graphene," Nature, vol. 438, no. 7065, pp. 201-204, 2005.

[40] A. K. Geim and K. S. Novoselov, "The rise of graphene," Nature Materials, vol. 6, no. 3, pp. 183-191, 2007.

[41] K. Naito, N. Yoshinaga, E. Tsutsumi, and Y. Akasaka, “Transparent conducting film composed of graphene and silver nanowire stacked layers," Synthetic Metals, vol. 175, pp. 42-46, 2013.

[42] X. Wang, L. Zhi, and K. Müllen, "Transparent, conductive graphene electrodes for dye-sensitized solar cells," Nano Letters, vol. 8, no. 1, pp. 323-327, 2008.

[43] C. Gómez-Navarro, R. T. Weitz, A. M. Bittner et al., "Electronic transport properties of individual chemically reduced graphene oxide sheets," Nano Letters, vol. 7, no. 11, pp. 3499-3503, 2007. 
[44] Y. Wang, X. Chen, Y. Zhong, F. Zhu, and K. P. Loh, "Large area, continuous, few-layered graphene as anodes in organic photovoltaic devices," Applied Physics Letters, vol. 95, no. 6, Article ID 063302, 2009.

[45] Y. Xu, G. Long, L. Huang et al., "Polymer photovoltaic devices with transparent graphene electrodes produced by spincasting," Carbon, vol. 48, no. 11, pp. 3308-3311, 2010.

[46] X. Wang, L. Zhi, N. Tsao, Ž. Tomović, J. Li, and K. Müllen, "Transparent carbon films as electrodes in organic solar cells," Angewandte Chemie, vol. 47, no. 16, pp. 2990-2992, 2008.

[47] L. Gómez De Arco, Y. Zhang, C. W. Schlenker, K. Ryu, M. E. Thompson, and C. Zhou, "Continuous, highly flexible, and transparent graphene films by chemical vapor deposition for organic photovoltaics," ACS Nano, vol. 4, no. 5, pp. 2865-2873, 2010.

[48] Y. U. Jung, S. Na, H. Kim, and S. Jun Kang, "Organic photovoltaic devices with low resistance multilayer graphene transparent electrodes," Journal of Vacuum Science \& Technology A: Vacuum, Surfaces, and Films, vol. 30, no. 5, Article ID 050604, 2012.

[49] M. Choe, B. H. Lee, G. Jo et al., "Efficient bulk-heterojunction photovoltaic cells with transparent multi-layer graphene electrodes," Organic Electronics, vol. 11, no. 11, pp. 1864-1869, 2010.

[50] Y.-Y. Choi, S. J. Kang, H.-K. Kim, W. M. Choi, and S.-I. Na, "Multilayer graphene films as transparent electrodes for organic photovoltaic devices," Solar Energy Materials and Solar Cells, vol. 96, no. 1, pp. 281-285, 2012.

[51] J. Geng, L. Liu, S. B. Yang et al., "A simple approach for preparing transparent conductive graphene films using the controlled chemical reduction of exfoliated graphene oxide in an aqueous suspension," Journal of Physical Chemistry C, vol. 114, no. 34, pp. 14433-14440, 2010.

[52] Y.-Y. Lee, K.-H. Tu, C.-C. Yu et al., “Top laminated graphene electrode in a semitransparent polymer solar cell by simultaneous thermal annealing/releasing method," ACS Nano, vol. 5, no. 8, pp. 6564-6570, 2011.

[53] M. Cox, A. Gorodetsky, B. Kim et al., "Single-layer graphene cathodes for organic photovoltaics," Applied Physics Letters, vol. 98, no. 12, Article ID 123303, 2011.

[54] Z. Liu, J. Li, Z.-H. Sun, G. Tai, S.-P. Lau, and F. Yan, “The application of highly doped single-layer graphene as the top electrodes of semitransparent organic solar cells," ACS Nano, vol. 6, no. 1, pp. 810-818, 2012.

[55] J.-H. Huang, J.-H. Fang, C.-C. Liu, and C.-W. Chu, "Effective work function modulation of graphene/carbon nanotube composite films as transparent cathodes for organic optoelectronics," ACS Nano, vol. 5, no. 8, pp. 6262-6271, 2011.

[56] Z. Liu, Q. Liu, Y. Huang et al., "Organic photovoltaic devices based on a novel acceptor material: graphene," Advanced Materials, vol. 20, no. 20, pp. 3924-3930, 2008.

[57] B. Thompson and J. Fréchet, "Polymer-fullerene composite solar cells," Angewandte Chemie International Edition, vol. 47, no. 1, pp. 58-77, 2008.

[58] Q. Liu, Z. Liu, X. Zhang et al., "Organic photovoltaic cells based on an acceptor of soluble graphene," Applied Physics Letters, vol. 92, no. 22, Article ID 223303, 2008.

[59] F. Yu and V. K. Kuppa, "Enhancement in the performance of organic photovoltaic devices with pristine graphene," Materials Letters, vol. 99, pp. 72-75, 2013.

[60] L. Ye, T. Xiao, N. Zhao et al., "Derivitization of pristine graphene for bulk heterojunction polymeric photovoltaic devices," Journal of Materials Chemistry, vol. 22, no. 33, pp. 16723-16727, 2012.
[61] Z. Liu, D. He, Y. Wang, H. Wu, and J. Wang, "Solutionprocessable functionalized graphene in donor/acceptor-type organic photovoltaic cells," Solar Energy Materials and Solar Cells, vol. 94, no. 7, pp. 1196-1200, 2010.

[62] D. Yu, K. Park, M. Durstock, and L. Dai, "Fullerene-grafted graphene for efficient bulk heterojunction polymer photovoltaic devices," The Journal of Physical Chemistry Letters, vol. 2, no. 10, pp. 1113-1118, 2011.

[63] S. Wang, B. M. Goh, K. K. Manga, Q. Bao, P. Yang, and K. P. Loh, "Graphene as atomic template and structural scaffold in the synthesis of graphene-organic hybrid wire with photovoltaic properties," ACS Nano, vol. 4, no. 10, pp. 6180-6186, 2010.

[64] Q. Liu, Z. Liu, X. Zhang et al., "Polymer photovoltaic cells based on solution-processable graphene and P3HT," Advanced Functional Materials, vol. 19, no. 6, pp. 894-904, 2009.

[65] J. Wang, Y. Wang, D. He et al., "Polymer bulk heterojunction photovoltaic devices based on complex donors and solutionprocessable functionalized graphene oxide," Solar Energy Materials and Solar Cells, vol. 96, no. 1, pp. 58-65, 2012.

[66] J. Wang, Y. Wang, D. He et al., "Composition and annealing effects in solution-processable functionalized graphene oxide/P3HT based solar cells," Synthetic Metals, vol. 160, no. 2324, pp. 2494-2500, 2010.

[67] Z. Liu, D. He, Y. Wang, H. Wu, and J. Wang, "Graphene doping of P3HT:PCBM photovoltaic devices," Synthetic Metals, vol. 160, no. 9-10, pp. 1036-1039, 2010.

[68] H. Ma, H. Yip, F. Huang, and A. K. Jen, "Interface engineering for organic electronics," Advanced Functional Materials, vol. 20, no. 9, pp. 1371-1388, 2010.

[69] V. Shrotriya, G. Li, Y. Yao, C.-W. Chu, and Y. Yang, "Transition metal oxides as the buffer layer for polymer photovoltaic cells," Applied Physics Letters, vol. 88, no. 7, Article ID 073508, 2006.

[70] M. D. Irwin, D. B. Buchholz, A. W. Hains, R. P. H. Chang, and T. J. Marks, " $p$-Type semiconducting nickel oxide as an efficiency-enhancing anode interfacial layer in polymer bulkheterojunction solar cells," Proceedings of the National Academy of Sciences of the United States of America, vol. 105, no. 8, pp. 2783-2787, 2008.

[71] J. Meyer, R. Khalandovsky, P. Görrn, and A. Kahn, " $\mathrm{MoO}_{3}$ films spin-coated from a nanoparticle suspension for efficient holeinjection in organic electronics," Advanced Materials, vol. 23, no. 1, pp. 70-73, 2011.

[72] Y.-H. Kim, S.-H. Lee, J. Noh, and S.-H. Han, "Performance and stability of electroluminescent device with self-assembled layers of poly(3,4-ethylenedioxythiophene)-poly(styrenesulfonate) and polyelectrolytes," Thin Solid Films, vol. 510, no. 1-2, pp. 305-310, 2006.

[73] J. Van De Lagemaat, T. M. Barnes, G. Rumbles et al., "Organic solar cells with carbon nanotubes replacing $\operatorname{In}_{2} \mathrm{O}_{3}: \mathrm{Sn}$ as the transparent electrode," Applied Physics Letters, vol. 88, no. 23, Article ID 233503, 2006.

[74] R. Steim, F. R. Kogler, and C. J. Brabec, "Interface materials for organic solar cells," Journal of Materials Chemistry, vol. 20, no. 13, pp. 2499-2512, 2010.

[75] J. Y. Kim, S. H. Kim, H.-H. Lee et al., "New architecture for high-efficiency polymer photovoltaic cells using solution-based titanium oxide as an optical spacer," Advanced Materials, vol. 18, no. 5, pp. 572-576, 2006.

[76] T.-Y. Chu, J. Lu, S. Beaupré et al., "Bulk heterojunction solar cells using thieno[3,4-c]pyrrole-4,6-dione and dithieno[3,2- b:2', $3^{\prime}$ d] silole copolymer with a power conversion efficiency of $7.3 \%$," 
Journal of the American Chemical Society, vol. 133, no. 12, pp. 4250-4253, 2011.

[77] Z. He, C. Zhong, X. Huang et al., "Simultaneous enhancement of open-circuit voltage, short-circuit current density, and fill factor in polymer solar cells," Advanced Materials, vol. 23, no. 40, pp. 4636-4643, 2011.

[78] S.-S. Li, K.-H. Tu, C.-C. Lin, C.-W. Chen, and M. Chhowalla, "Solution-processable graphene oxide as an efficient hole transport layer in polymer solar cells," ACS Nano, vol. 4, no. 6, pp. 3169-3174, 2010.

[79] M. S. Ryu and J. Jang, "Effect of solution processed graphene oxide/nickel oxide bi-layer on cell performance of bulkheterojunction organic photovoltaic," Solar Energy Materials and Solar Cells, vol. 95, no. 10, pp. 2893-2896, 2011.

[80] K. C. Kwon, W. J. Dong, G. H. Jung, J. Ham, J.-L. Lee, and S. Y. Kim, "Extension of stability in organic photovoltaic cells using UV/ozone-treated graphene sheets," Solar Energy Materials \& Solar Cells, vol. 109, pp. 148-154, 2013.

[81] Y.-J. Jeon, J.-M. Yun, D.-Y. Kim, S.-I. Na, and S.-S. Kim, "Highperformance polymer solar cells with moderately reduced graphene oxide as an efficient hole transporting layer," Solar Energy Materials and Solar Cells, vol. 105, pp. 96-102, 2012.

[82] J. Liu, Y. Xue, and L. Dai, "Sulfated graphene oxide as a hole-extraction layer in high-performance polymer solar cells," Journal of Physical Chemistry Letters, vol. 3, no. 14, pp. 19281933, 2012.

[83] J. Liu, Y. Xue, Y. Gao, D. Yu, M. Durstock, and L. Dai, "Hole and electron extraction layers based on graphene oxide derivatives for high-performance bulk heterojunction solar cells," Advanced Materials, vol. 24, no. 17, pp. 2228-2233, 2012.

[84] S. Qu, M. Li, L. Xie et al., "Noncovalent functionalization of graphene attaching [6,6]-phenyl-C61-butyric acid methyl ester (PCBM) and application as electron extraction layer of polymer solar cells," ACS Nano, vol. 7, no. 5, pp. 4070-4081, 2013.

[85] D. D. Nguyen, N. H. Tai, Y. L. Chueh et al., "Synthesis of ethanol-soluble few-layer graphene nanosheets for flexible and transparent conducting composite films," Nanotechnology, vol. 22, no. 29, Article ID 295606, 2011.

[86] B. Yin, Q. Liu, L. Yang et al., "Buffer layer of PEDOT:PSS/ graphene composite for polymer solar cells," Journal of Nanoscience and Nanotechnology, vol. 10, no. 3, pp. 1934-1938, 2010. 

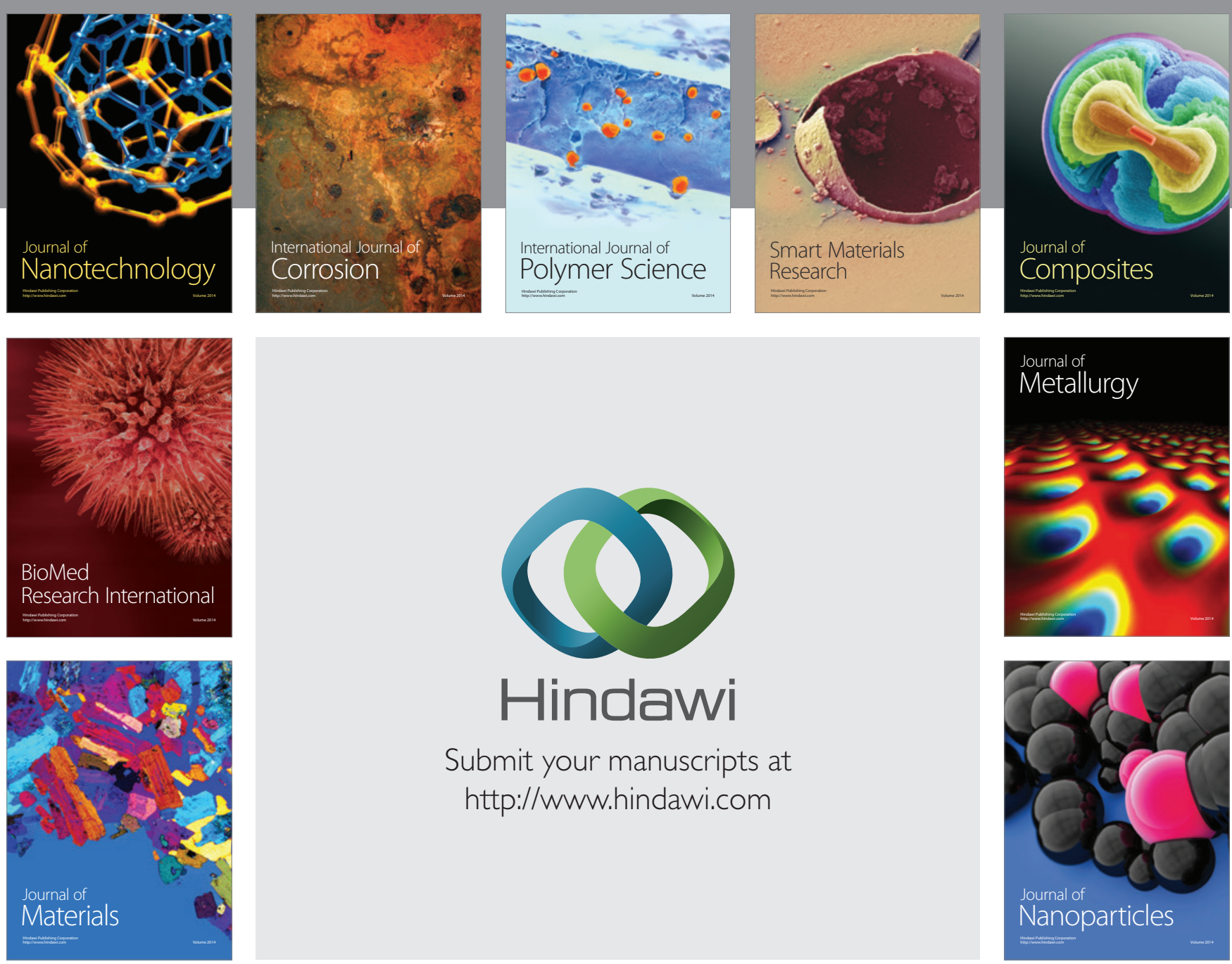

Submit your manuscripts at http://www.hindawi.com
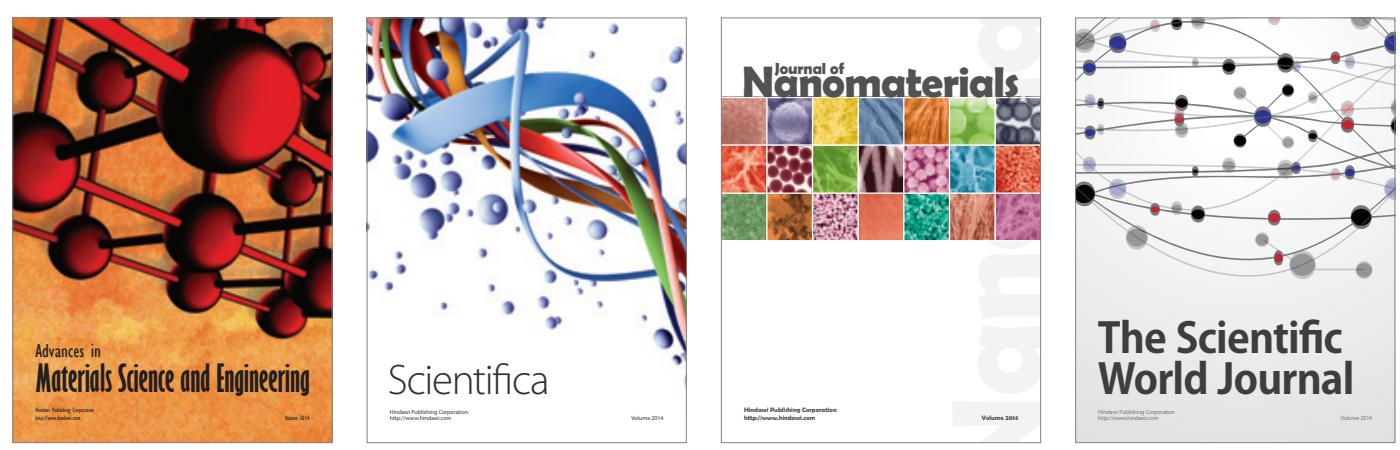

\section{The Scientific World Journal}
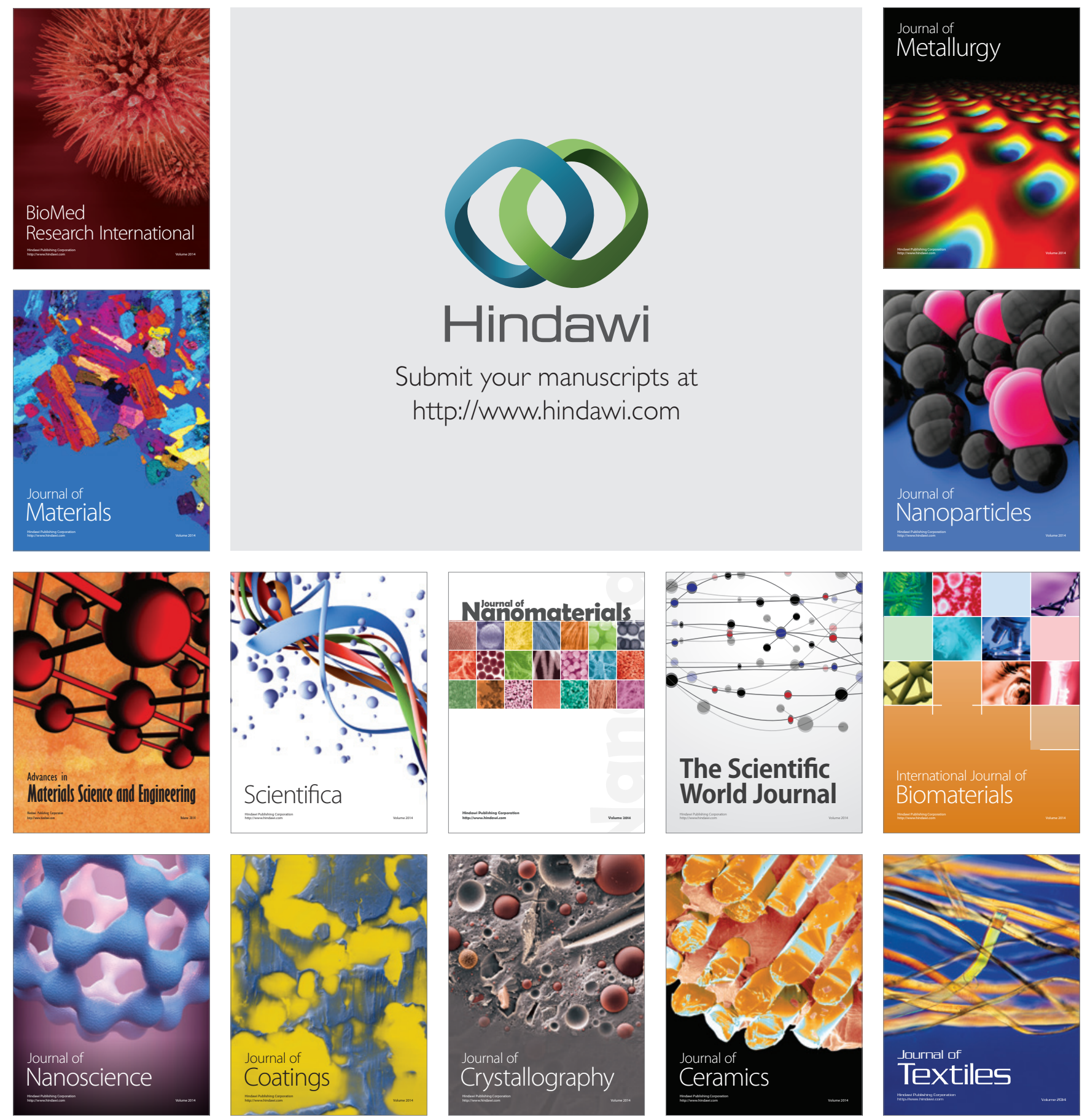